\title{
๖The Process of High-Frequency Intraseasonal Oscillation Associated with a Persistent Rainfall Event over South China
}

\author{
BIN ZHENG, ${ }^{\mathrm{a}, \mathrm{b}}$ YANYAN HUANG, ${ }^{\mathrm{a}, \mathrm{b}}$ AND AILAN LIN ${ }^{\mathrm{a}, \mathrm{b}}$ \\ ${ }^{a}$ Institute of Tropical and Marine Meteorology, China Meteorological Administration, Guangzhou, China \\ ${ }^{\mathrm{b}}$ Guangdong Provincial Key Laboratory of Regional Numerical Weather Prediction, Guangzhou, China
}

(Manuscript received 11 June 2021, in final form 19 October 2021)

\begin{abstract}
In the present study, the moist static energy (MSE) budget associated with a persistent rainfall event that occurred over South China in late August 2018 (PR1808) was analyzed using ERA-Interim data. The results revealed that the PR1808 event was closely related to a 12-30-day intraseasonal oscillation (ISO), with a significant westwardpropagating mode. The recharge of MSE occurred before ISO deep convection, and the MSE was discharged during and after the peak precipitation. This result indicates that the recharge-discharge cycle of MSE played an important role in regulating the high-frequency ISO (HF-ISO) process during the PR1808 event. However, the midlevel MSE tendency, rather than the low-level tendency, controlled the column-integrated MSE change in this case, and there was no low-level MSE tendency ahead of HF-ISO convection, which is different from previous studies, implying that shallow convection was not a key factor in this case. The recharge of MSE related to the midlevel MSE change mode was mainly attributed to zonal advection, while the forcing related to radiative heating (longwave and shortwave radiation) and heat fluxes (latent and sensible heat fluxes) contributed little to the change in MSE. Furthermore, for the zonal advection of MSE, the main contribution originated from the advection by the low-frequency zonal flow across the low-frequency MSE gradient, and interactions between high- (low-) frequency zonal flow and low- (high-) frequency MSE. In addition, the disturbances from higher latitudes enhanced the persistent rainfall in this case over South China through the southward shift of baroclinic vorticity.
\end{abstract}

KEYWORDS: Advection; Extreme events; Rainfall; Moisture/moisture budget; Vorticity

\section{Introduction}

Persistent rainfall is among the most common meteorological disasters during the flood season in China, and often leads to severe disasters such as floods, mudslides, and landslides. In mainland China, the greatest annual mean precipitation, the most rainstorms, and the longest rainy season usually occur in South China, as the area is affected by both tropical and subtropical summer monsoons. Persistent rainfall occurs several times a year in South China, usually between March and October (Hu et al. 2007).

The persistent rainfall process over South China is closely connected to the intraseasonal oscillation (ISO; Ren et al. 2013; Li et al. 2015; Hui and Fang 2016a,b; Li et al. 2016; Wang et al. 2017). Generally, ISOs include high-frequency (HF) and low-frequency (LF) oscillations with periods of 10-20 (or 10-30) and 30-60 days, respectively (Mao and Chan 2005; Krishnamurthy and Shukla 2007; Li et al. 2015; Hui and Fang 2016a,b; Li et al. 2018; Zheng and Huang 2019). Over the lower reaches of the Yangtze River basin (LYRB), the 10-30-day mode has an intensity comparable to that of the 30-90-day mode (Yang et al. 2010; Zhu et al. 2017), whereas in South China, the intensity of the 10-30-day mode is much greater than that of the 30-60-day mode ( $\mathrm{Li}$ et al. 2015). This

¿ Denotes content that is immediately available upon publication as open access.

Corresponding author: Bin Zheng, zhb@ustc.edu difference does not rule out that the 30-90-day mode is dominant in some years (Zhu and Li 2017). Figure 1 shows that the variance in the 10-30-day ISO is 2-4 times larger than that of the 30-60-day ISO in South China (Figs. 1c,d), although the synoptic-scale component provides the largest contribution to the precipitation anomalies (Figs. 1a,b). Persistent rainfall over South China should be impacted by the South China Sea and western North Pacific ISOs with northward or northwestward propagation (Mao and Chan 2005; Chen et al. 2015; Li et al. 2015; Gao et al. 2016; Hsu et al. 2016; Zheng and Huang 2018; Zheng et al. 2020), since the South China Sea/western North Pacific exhibits the largest intraseasonal variability during boreal summer (Kemball-Cook and Wang 2001; Li et al. 2018).

Background flows and moisture play key roles in the propagation and development of the tropical ISO. The main background flows impacting the persistent rainfall over East Asia come from summer and winter monsoons (Zheng et al. 2007; Li et al. 2014; Imada et al. 2015; Liu et al. 2016). In addition, over southern China, sufficient water vapor associated with a persistent rainfall process mainly originates from three pathways - the tropical Indian Ocean, the South China Sea, and the western North Pacific. The spring rainfall over southern China, namely, the persistent rainfall from midMarch to mid-May, generally corresponds to the western North Pacific moisture source (Lin et al. 2013; Lin et al. 2014; Zhang et al. 2015). The increase in the land-sea thermal contrast plays an important role in this moisture pathway (Tian and Yasunari 1998; Zhu et al. 2012; Zhang et al. 2013). When the South China Sea summer monsoon breaks out, the 

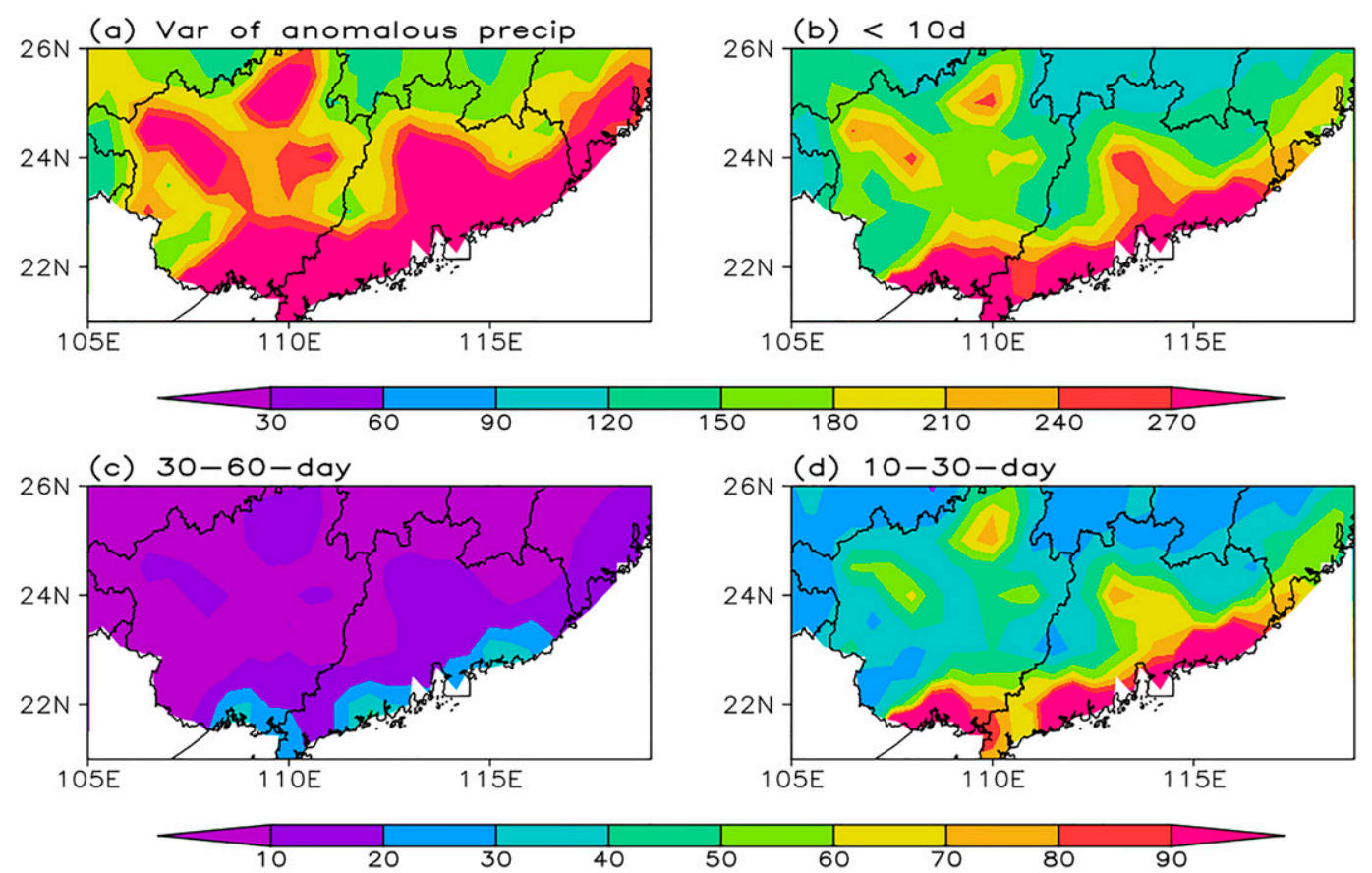

FIG. 1. Climatological mean (1961-2017) variance distribution of May-September (a) precipitation anomalies and (b) synoptic, (c) 30-60-day, and (d) 10-30-day components in South China with a unit of (mm day $\left.{ }^{-1}\right)^{2}$.

South China Sea is the main source of water vapor related to the persistent rainfall over South China from mid-May to late August (Liu et al. 2016). From late July to early October, the moisture in the persistent rainfall process mainly originates from the Indian Ocean and the principal rainfall belts appear east of southern China (Liu et al. 2016).

In contrast, a buildup of column moist static energy (MSE) occurs before ISO deep convection, and MSE is discharged during and after ISO convection (Hendon and Liebmann 1990; Kemball-Cook and Weare 2001; Maloney 2009). This process is the so-called charge-discharge cycle. Many previous studies have used the column-integrated MSE tendency to understand the development and propagation of the ISO convection (Raymond and Fuchs 2009; Sobel and Maloney 2012, 2013; Kim et al. 2014; Adames and Kim 2016), while the MSE tendency related to ISO convection is mainly attributed to horizontal MSE advection in lower troposphere (Kim et al. 2014; Sobel et al. 2014; Adames and Wallace 2015; Jiang 2017; Wang and Li 2020). This understanding implies that a low-level MSE change determines the column-integrated MSE tendency which is closely linked to the development and propagation of ISO convection.

A persistent rainfall event occurred over South China in late August 2018 (PR1808), and this study attempted to analyze the persistent rainfall event in terms of the MSE budget. The next section describes the datasets and method used in this investigation. The power spectra and circulation characteristics associated with the persistent rainfall event over South China are presented in section 3. Section 4 presents the relationship between the MSE change and the intraseasonal precipitation and MSE budget during the persistent rainfall event over South China. The key factors in affecting the ISO associated with the PR1808 event are analyzed in sections 5 and 6 , which are followed by a summary and discussion.

\section{Data and analysis method}

\section{a. Datasets}

In this study, most of the data, including wind, water vapor, geopotential height, air temperature, vorticity, divergence, surface fluxes (surface solar radiation, longwave radiation, latent heat, and sensible heat fluxes), top-of-the-atmosphere net radiation, total precipitation, and sea surface/land skin temperature, were taken from the ERA-Interim (Dee et al. 2011) with a $1^{\circ} \times 1^{\circ}$ grid resolution. Notably, in this study, we reversed the signs of the fluxes; thus, positive flux values indicate that the energy is transferred upward. For comparison, we introduce another set of daily precipitation data from the Global Precipitation Climatology Project (GPCP) satellite-derived infrared (IR) GOES precipitation index (GPI) daily rainfall estimates (Huffman, et al. 2001) with a $1^{\circ} \times 1^{\circ}$ grid resolution.

\section{b. Analytical method}

In this study, the South China region was defined as an area from $20^{\circ}$ to $25^{\circ} \mathrm{N}$ and $105^{\circ}$ to $120^{\circ} \mathrm{E}$. Anomalous variables represented the deviation from the climatological mean, which was from 1981 to 2010 for the ERA-Interim and 1997-2016 for the GPI data. MSE was used to determine the ISO processes associated with the PR1808 event. MSE is defined as $m=c_{p} T+\Phi+L q$, where $T$ is temperature, $c_{p}$ is the specific heat at constant pressure, $\Phi$ is geopotential, $L$ is the latent heat of vaporization at $0^{\circ} \mathrm{C}$, and $q$ is the specific humidity. A Hovmöller diagram was introduced to understand the propagation of the ISO. Furthermore, 

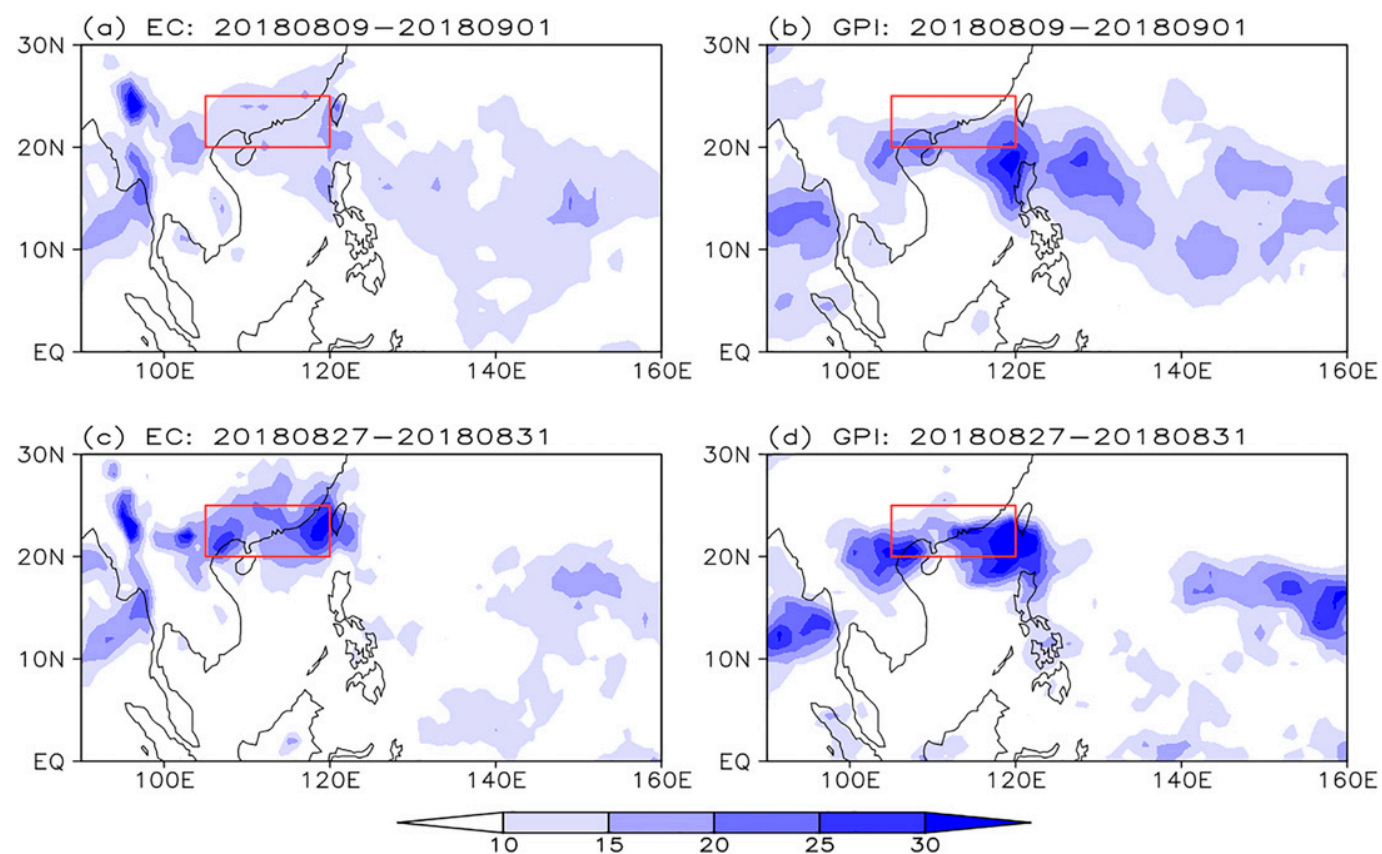

FIG. 2. Spatial patterns of precipitation from 9 Aug to 1 Sep with (a) the GPI and (b) the ERA-Interim data. (c),(d) As in (a) and (b), but for the period from 27 to 31 Aug. The red box denotes the South China region $\left(20^{\circ}-25^{\circ} \mathrm{N}, 105^{\circ}-120^{\circ} \mathrm{E}\right)$.

power spectrum analysis and correlation analysis were also employed in this study.

\section{Persistent rainfall event in SC}

A persistent rainfall event occurred over South China in late August 2018 (PR1808). The spatial pattern of precipitation is shown in Fig. 2, which shows that the precipitation from 9 August to 1 September in South China is significantly less than that from
27 August to 31 August, and the latter is the main process of PR1808 and the focus of this study. Notably, some enlargement or reduction in the defined South China region has little impact on the analysis (figure not shown), which indicates that the analysis is not sensitive to the selection of the South China region.

Figure 3 a shows the daily regional precipitation over South China from GPI data, with a value $>1$ standard deviation sustained from 9 August to 1 September 2018 and a maximum value that approached $30 \mathrm{~mm}_{\text {day }^{-1}}$. Two evident processes,
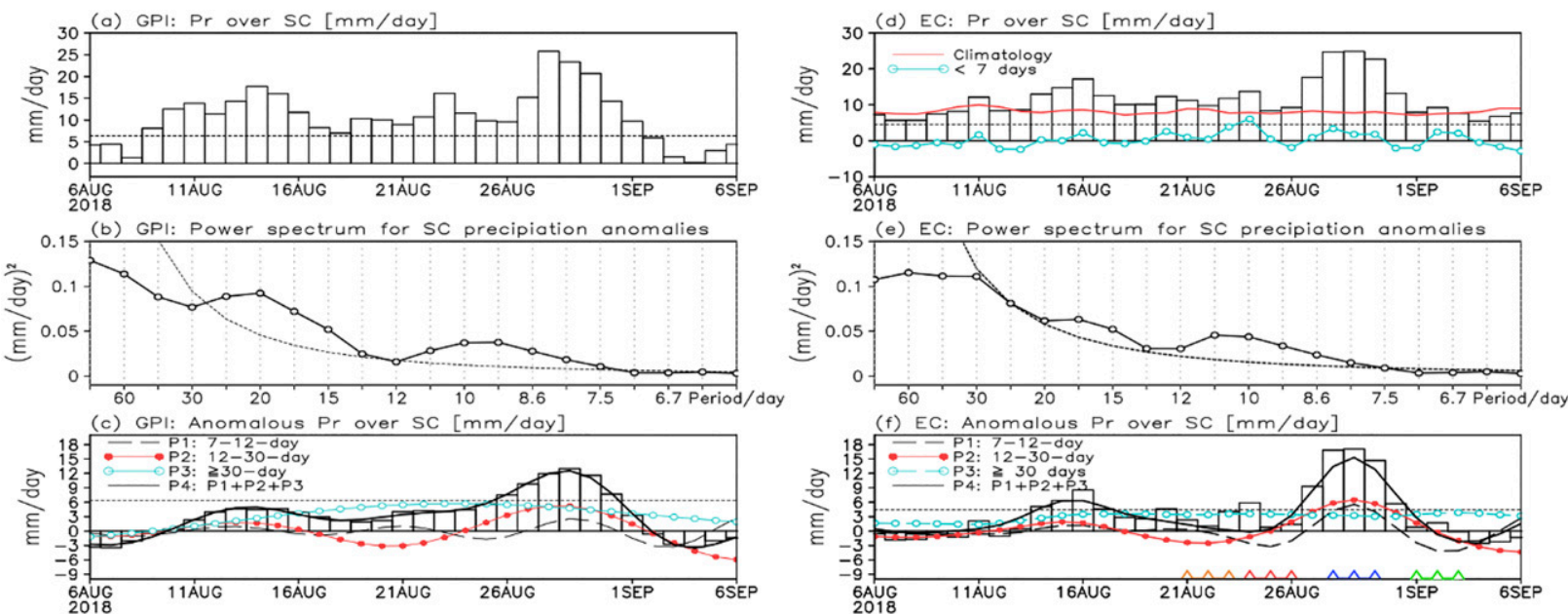

FIG. 3. (a) Time series of daily precipitation over South China from the GPI, (b) power spectrum, and (c) scale-separated precipitation anomalies. (d)-(f) As in (a)-(c), but for the ERA-Interim data. The short-dashed lines in (a), (d), (c) and (f) denote one standard deviation, and the $95 \%$ confidence level for (b) and (e). The orange, red, blue, and green triangle marks in (f) denote the suppressed, developing, active, and decaying phases, respectively. 


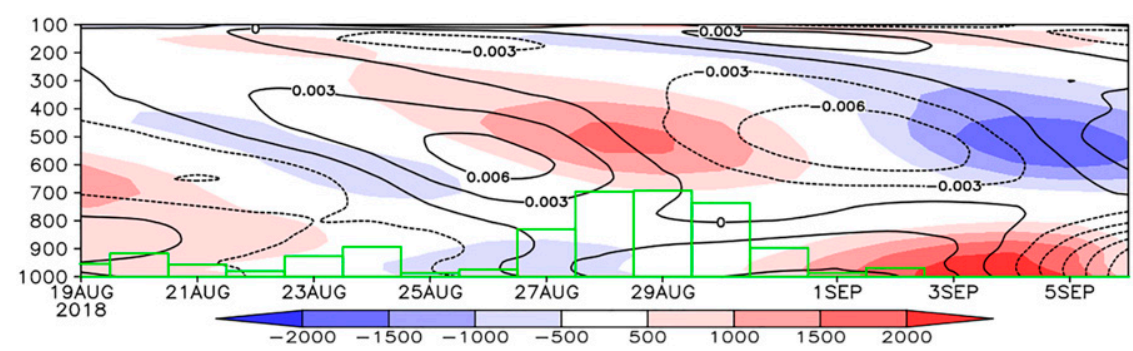

FIG. 4. HF intraseasonal MSE anomalies (shading, $\mathrm{J} \mathrm{kg}^{-1}$ ) and tendency (contours, $\mathrm{W} \mathrm{kg}^{-1}$ ) averaged over South China. Green bars denote precipitation anomalies $\left(\mathrm{mm} \mathrm{day}^{-1}\right)$.

9-18 August and 21 August-1 September, are observed from the precipitation averaged over South China (Fig. 3a). The precipitation anomalies (the column in Fig. 3c) indicate that the latter was dominant. Figure $3 b$ presents the power spectrum analysis results, which shows that there were two main periods of summer precipitation over South China in 2018: a weekly period of 7-12 days and a period of 12-30 days. Figure 3c shows 7-12-day, 12-30-day, and LF ( $>30$ days) components of the precipitation anomalies over South China. The LF component had a significantly different pattern (the open squares in Fig. 2c) from that of the actual variations (the bars in Figs. 3c,f). In contrast, the 12-30-day bandpass-filtered precipitation (the solid circles in Fig. 3c) exhibited the most similar pattern and the greatest contribution to the precipitation anomalies. The results from the ERA-Interim data (Figs. 3d-f) are nearly consistent with Figs. 3a-c. Therefore, the following analysis focused on the 12-30-day oscillation (hereafter referred to as the high-frequency intraseasonal oscillation, HF-ISO) based on the ERA-Interim.

In addition, we can see from Fig. 3d that the contribution of the synoptic-scale component in this case is very small, while $\mathrm{P} 4(\mathrm{P} 1+\mathrm{P} 2+\mathrm{P} 3)$ in Fig. $3 \mathrm{f}$ accounts for approximately $2 / 3$ of the total precipitation (almost all anomalous precipitation). We divided the main process of the PR1808 event into four phases. In Fig. 3f, orange represents the suppressed phase on the day of the precipitation minimum and 1 day before and after, red is the developing phase on the day when the precipitation anomaly is closest to zero and 1 day before and after, blue is the active phase on the day of the precipitation maximum and 1 day before and after, and green is the decaying phase with the same definition as the developing phase but after the precipitation maximum. Thus, the PR1808 event was examined during the period from 21 August to 3 September.

The intraseasonal MSE related to the PR1808 event is shown in Fig. 4. The intraseasonal MSE in the middle troposphere and precipitation anomaly were nearly in phase over $\mathrm{SC}$, whereas the MSE in the lower troposphere lagged the precipitation anomaly. Moreover, a positive midlevel MSE tendency occurred before PR1808, while a positive low-level MSE tendency appeared after PR1808. This result implies that the midlevel MSE tendency controlled the development of this persistent rainfall event rather than the low-level MSE tendency, which is very different from the previous understanding.

Figure 5 shows the 12-30-day filtered precipitation, $850-\mathrm{hPa}$ vorticity, and $850-\mathrm{hPa}$ winds based on the different phases of the
PR1808 event (as shown in Fig. 3f). During the suppressed phase, an anticyclonic anomaly appeared over the tropical western North Pacific, and a wave train-like disturbance occurred to the north (Fig. 5a). In the developing and active phases, the anomalous anticyclone moved northward and was embedded in the southwestward-propagating wave train (Figs. 5b,c), and a cyclonic anomaly began to appear in the tropical western North Pacific (Fig. 5c). In the decaying phase, the enhanced cyclonic anomaly moved northward again (Fig. 5d). In contrast, the precipitation anomaly shifted westward during the suppressed phase and throughout the active phase and then turned north in the decaying phase (Fig. 5). While a low-level wave train-like disturbance propagated southwestward from the higher latitudes to SC, an evident feature of southwestward propagation was apparent at the high level (Fig. 6).

In Fig. 5, the low-level anticyclonic anomalies controlled the western North Pacific before the active phase of the PR1808 event. Over the Asian region south of $30^{\circ} \mathrm{N}$, although not obvious before the active phase, the high-level anticyclone was strengthened due to the enhanced cyclonic anomaly at higher latitudes (Figs. 6a-c). These results indicate that the South Asian high and the western Pacific subtropical high were stronger before the PR1808 event.

$\mathrm{Li}$ et al. (2015) revealed that the subseasonal oscillations related to the persistent rainfall in South China are characterized by a northwest-southeast-oriented wave train pattern with a pronounced baroclinic vertical structure, moving northwestward. However, the characteristics of the PR1808 event were significantly different from those of previous studies. First, the PR1808 event was affected by higher-latitude waves rather than tropical waves (Figs. 5 and 6; the specific processes will be analyzed later). Second, the precipitation anomaly propagated westward during the PR1808 event (Fig. 5), while northward or northwestward propagation has been revealed in many previous studies (Mao and Chan 2005; Chen et al. 2015; Li et al. 2015; Gao et al. 2016; Hsu et al. 2016; Zheng and Huang 2018; Zheng et al. 2020). Since the PR1808 event was quite different from most other persistent rainfalls over South China, it is worth exploring the causes of this case to help understand the midlevel MSE change mode.

\section{Vertically integrated MSE budget}

\section{a. Relationship between $m$ and HF-ISO}

The $m$ (i.e., MSE) and precipitation were nearly in phase on the ISO time scale over South China (Fig. 4), which is 

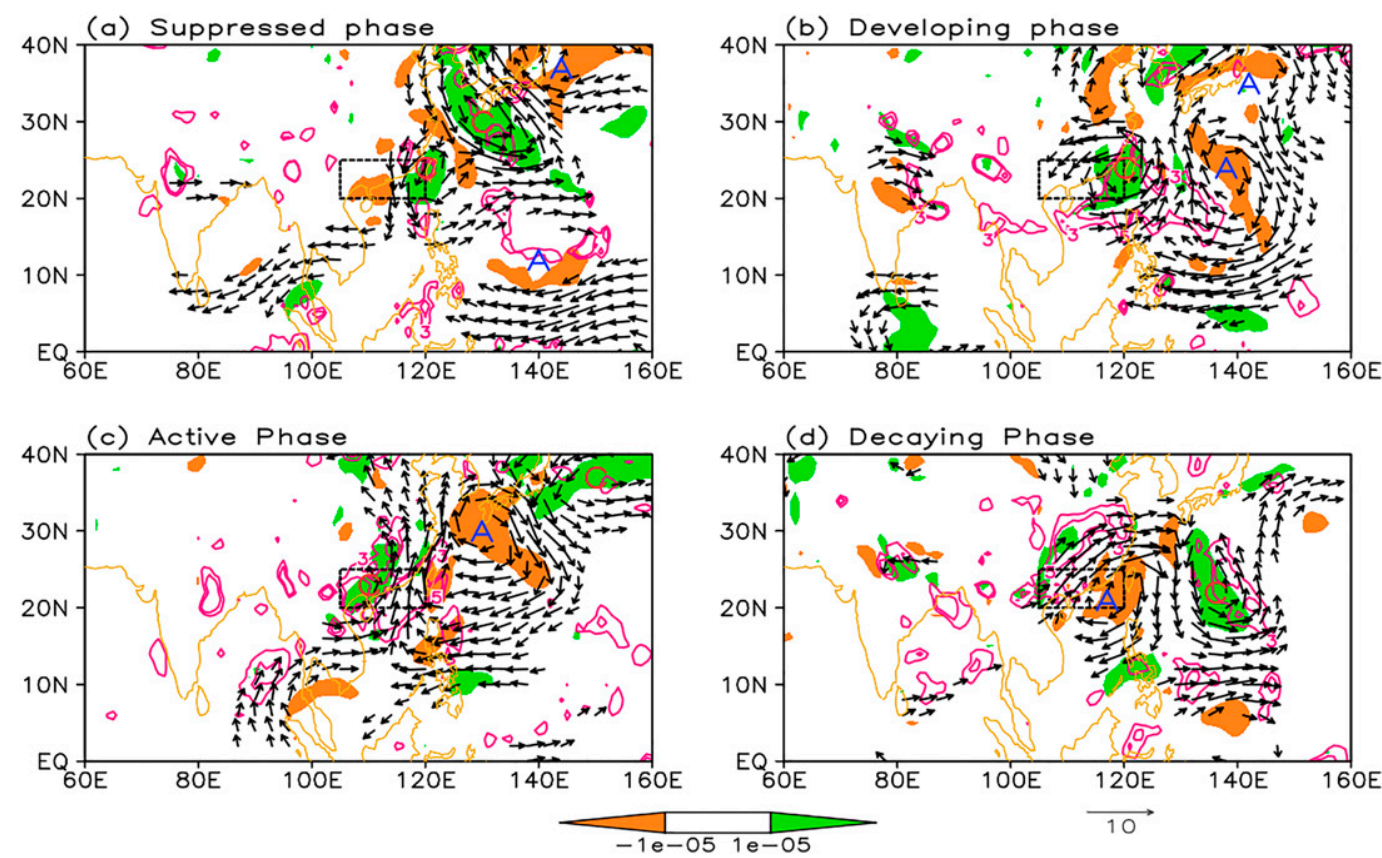

FIG. 5. The 12-30-day filtered precipitation (contours, $\mathrm{mm} \mathrm{day}^{-1}$ ), $850-\mathrm{hPa}$ relative vorticity $\left(\mathrm{s}^{-1}\right)$, and $850-\mathrm{hPa}$ winds (vectors, $\mathrm{m} \mathrm{s}^{-1}$ ) during the (a) suppressed, (b) developing, (c) active, and (d) decaying phases. The box with a dashed outline denotes the South China region $\left(20^{\circ}-25^{\circ} \mathrm{N}, 105^{\circ}-120^{\circ} \mathrm{E}\right)$. To focus on the key features, only anomalous precipitation $>3 \mathrm{~mm} \mathrm{day}^{-1}$ and wind speeds $>2 \mathrm{~m} \mathrm{~s}^{-1}$ are shown, while vorticity anomalies between $-10^{-5}$ and $10^{-5} \mathrm{~s}^{-1}$ are omitted. The letters $\mathrm{A}$ and $\mathrm{C}$ indicate anomalous anticyclones and cyclones, respectively.

consistent with the findings of previous studies (Maloney 2009; Gao et al. 2019; Wang and Li 2020). Moreover, the overall spatial patterns of $m$ and precipitation are also consistent in different phases (figure not shown). The relationship between the change in vertically integrated $m$ and precipitation is examined on the HF intraseasonal time scale (Fig. 7). During the suppressed phase of the PR1808 process, the main positive change in $m$ was located in the western North Pacific to the eas of South China (Fig. 7a), and in the subsequent developing phase, the enhanced convection occurred over the western North Pacific to the east of South China, while the main positive change of $m$ appeared in eastern China (Fig. 7b). Then, the enhanced precipitation and northwestward movement of the positive $m$ change occurred over South China during the active phase (Fig. 7c). In Fig. 7d, the convection center appears over the northwest of South China. In general, the positive change in $m$ preceded the convection center, and when the precipitation reached its maximum, $m$ began to decrease, which is consistent with the charge-discharge mechanism (Hendon and Liebmann 1990; Kemball-Cook and Weare 2001; Maloney 2009).

To observe the westward propagation mode more clearly, a lead-lag correlation analysis was performed, as shown in Fig. 8. In Fig. 8, convection propagates westward, and the $m$ tendency is always ahead of the convection center. The tropical convection moved northwestward, but it had little effect on the PR1808 event.

In previous studies, low-level $m$ (or specific humidity) leads a column-integrated $m$ (e.g., Kemball-Cook and Weare 2001; Jiang et al. 2004; Maloney 2009; Zheng and Huang 2018; 2019; Zheng and Huang 2019), and then a large convective instability appears before the precipitation maximum ( $\mathrm{Li}$ et al. 2013; Zheng et al. 2020), favoring ISO convection development. In this case, column $m$ (or specific humidity) was dominated by midlevel $m$ (Figs. 9a,b), while low-level $m$ had a negative contribution (Fig. 4). This result implied that shallow convection was not a key factor in this case. Using a climate model, research in Maloney (2009) showed that ISO convection can develop via horizontal advection, even though shallow convection plays only a modest role. Therefore, other physical mechanisms, in addition to shallow convection development, must contribute to the ISO convection associated with the PR1808 event. In Fig. 9e, reduced convective instability appeared in the low-level troposphere before the ISO convection peak, while it increased in the middle level. Correspondingly, the vertical motion was weakened in the lower level and strengthened in the middle level (Fig. 9f). This finding confirms that the ISO convection was directly developed from the middle level rather than the lower level in this case.

In addition, the changes in heating rate by condensation and $m$ (or specific humidity) were nearly in phase (Figs. 9a-c), given that the former was generally proportional to the latter (e.g., Charney and Ellassen 1964). Thus, a low-level convergence appeared before ISO convection. Nevertheless, the enhanced moisture convergence at the lower level was offset by the negative change in $m$ (or specific humidity). Therefore, there is no evident positive moisture anomaly ahead of precipitation maximum at the lower level in this case. In contrast, the ascending movement was strengthened at the middle level, further promoting the development of ISO convection. 

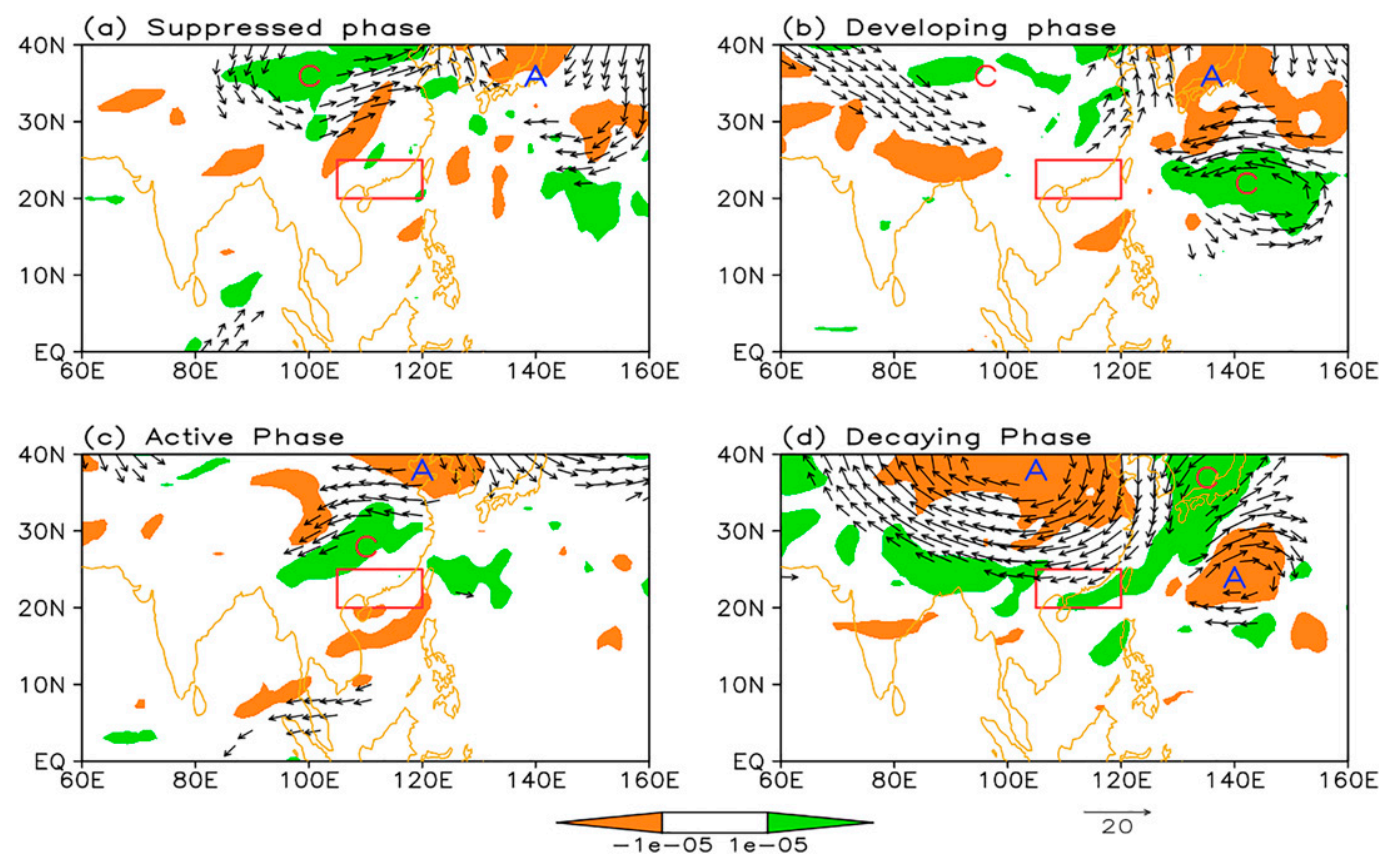

FIG. 6. As in Fig. 5, but for 200-hPa relative vorticity and winds.

Thus, what caused the positive tendency of the MSE? This question will be discussed in the following subsections.

\section{b. Moist static energy budget}

The relationship between the $m$ budget and precipitation anomalies over South China was examined. Following Neelin and Held (1987), the vertically integrated $m$ budget can be written as

$$
\left\langle\frac{\partial m}{\partial t}\right\rangle+\left\langle\omega \frac{\partial m}{\partial p}\right\rangle+\langle\mathbf{v} \cdot \nabla m\rangle=\mathrm{LH}+\mathrm{SH}+\langle\mathrm{LW}\rangle+\langle\mathrm{SW}\rangle
$$
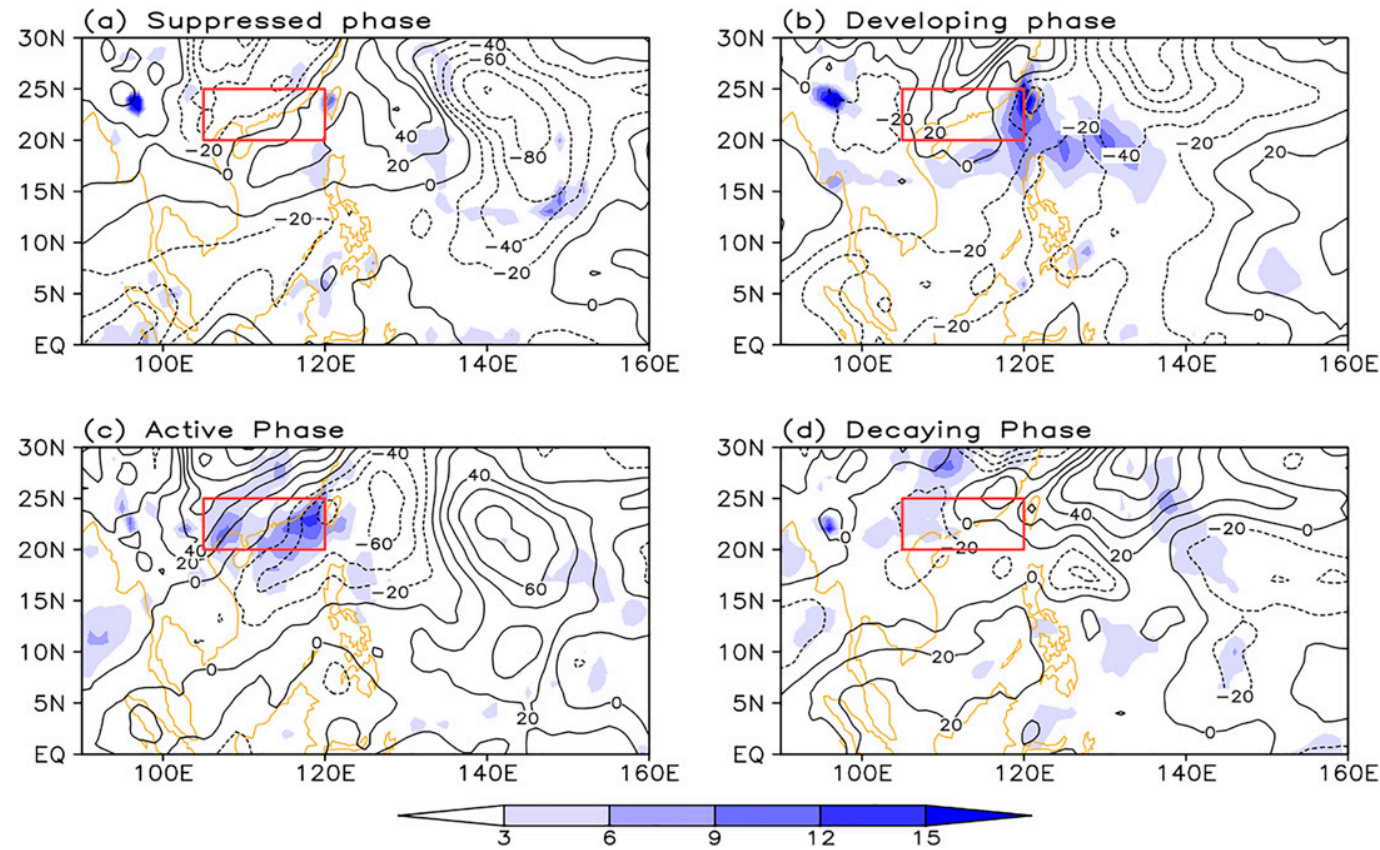

FIG. 7. Vertically integrated $m$ tendency (contours, $\mathrm{W} \mathrm{m}^{-2}$ ) and precipitation anomalies (shading, $\mathrm{mm} \mathrm{day}^{-1}$ ) in (a) suppressed, (b) developing, (c) active, and (d) decaying phases. The red box denotes the South China region $\left(20^{\circ}-25^{\circ} \mathrm{N}, 105^{\circ}-120^{\circ} \mathrm{E}\right)$. 

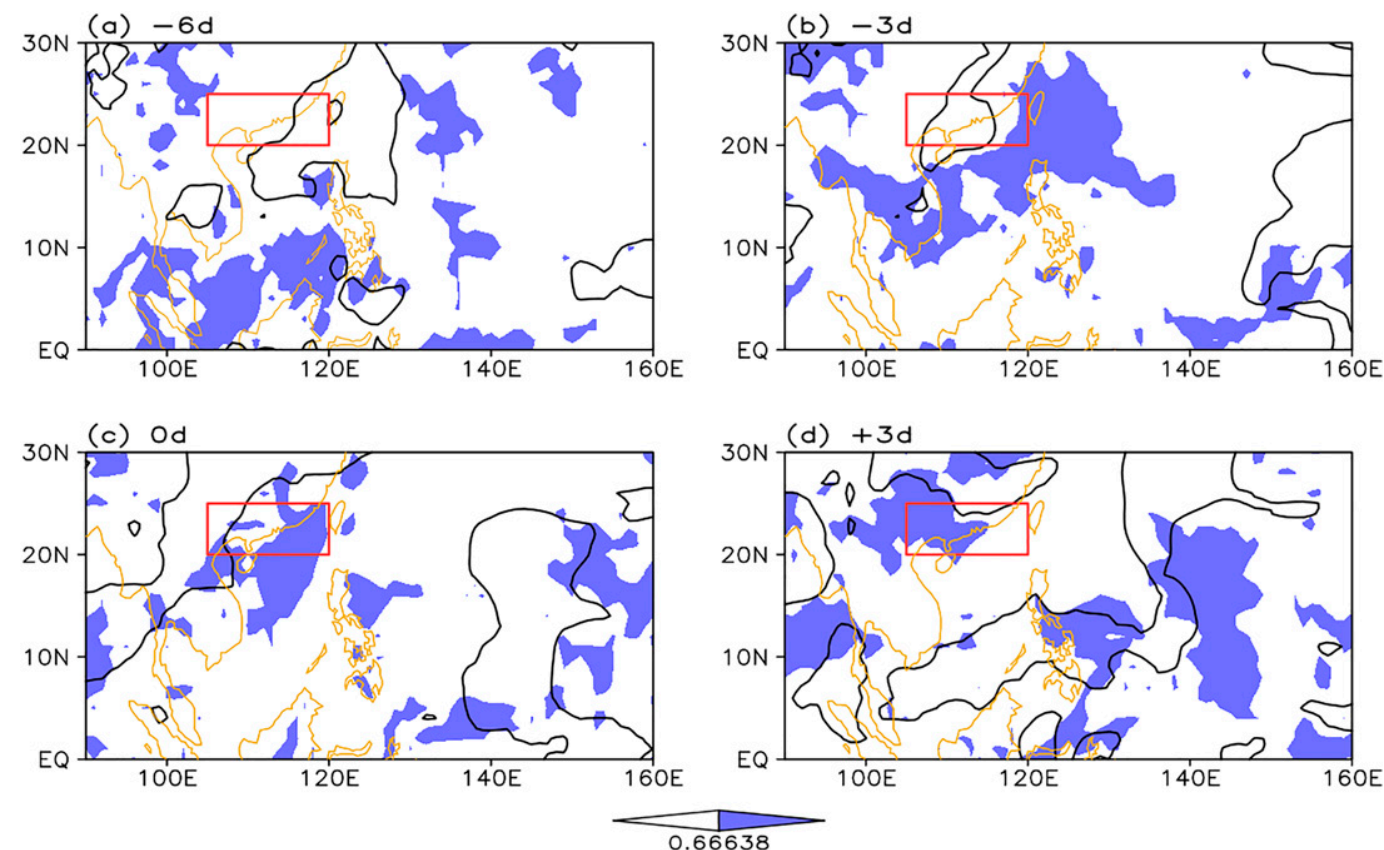

FIG. 8. Lead-lag correlation coefficients between South China precipitation and precipitation (shading) and vertically integrated $m$ tendency (contours) on a 10-30-day time scale. Only the correlation coefficients with $95 \%$ significance levels are displayed. Here the minus sign denotes South China precipitation lags precipitation and vertically integrated $m$ tendency, and the plus sign means a lead correlation. The red box denotes the South China region $\left(20^{\circ}-25^{\circ} \mathrm{N}, 105^{\circ}-120^{\circ} \mathrm{E}\right)$.

where the angle brackets represent a mass-weighted vertical integral from the surface (here, taken as $1000 \mathrm{hPa}$ ) to the top of the troposphere (here, taken as $100 \mathrm{hPa}$ ), $p$ is the pressure, $\mathbf{v}$ is the horizontal wind vector, and $\omega$ is the vertical pressure velocity. The first term on the left in Eq. (1) represents the vertically integrated $m$ tendency, the second term denotes the column-integrated change in $m$ due to vertical advection, and the third term represents the horizontal advection of $m$. LH is
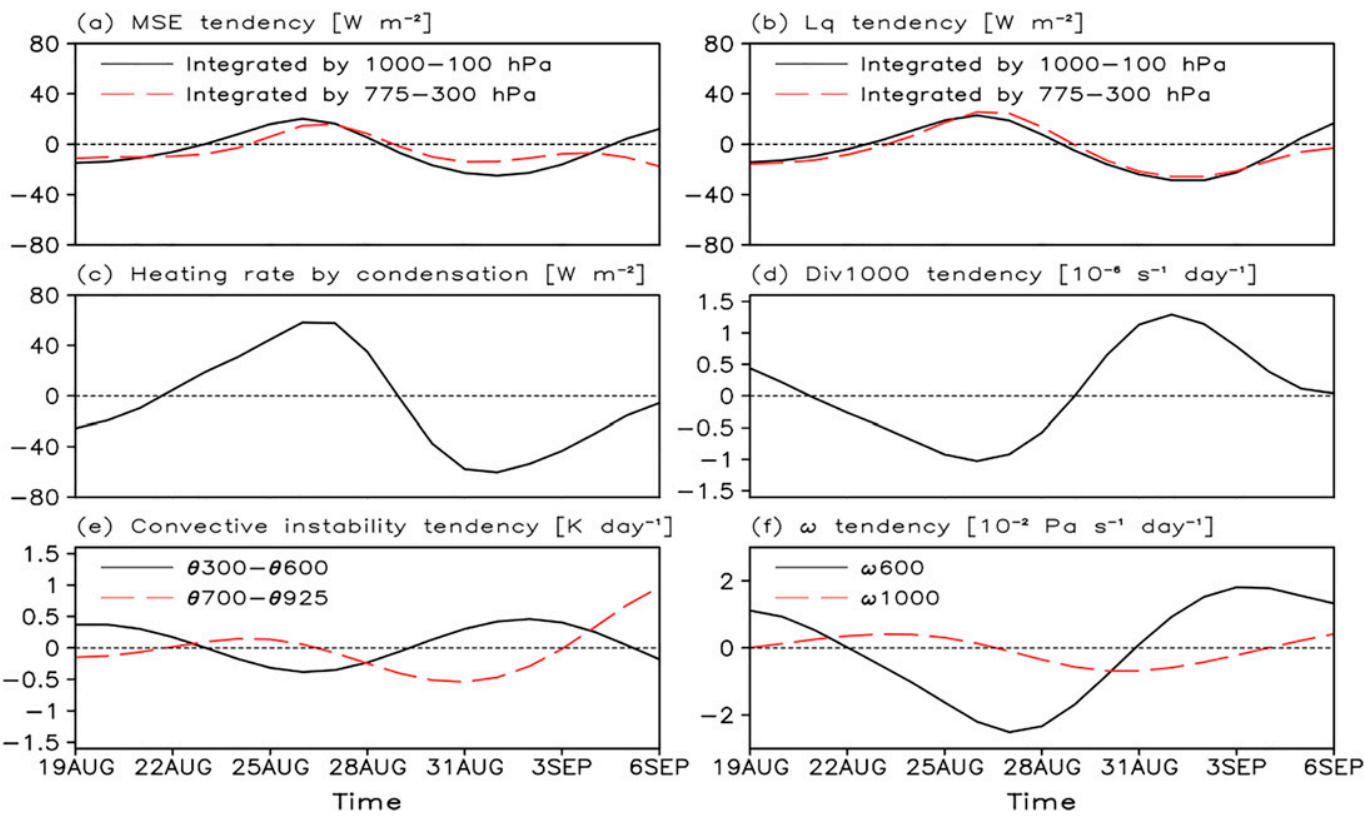

FIG. 9. Tendency of (a) MSE, (b) latent heat energy ( $L q)$, (c) heating rate by condensation, (d) divergence at $1000 \mathrm{hPa}$, (e) convective instability, and (f) vertical velocity. 

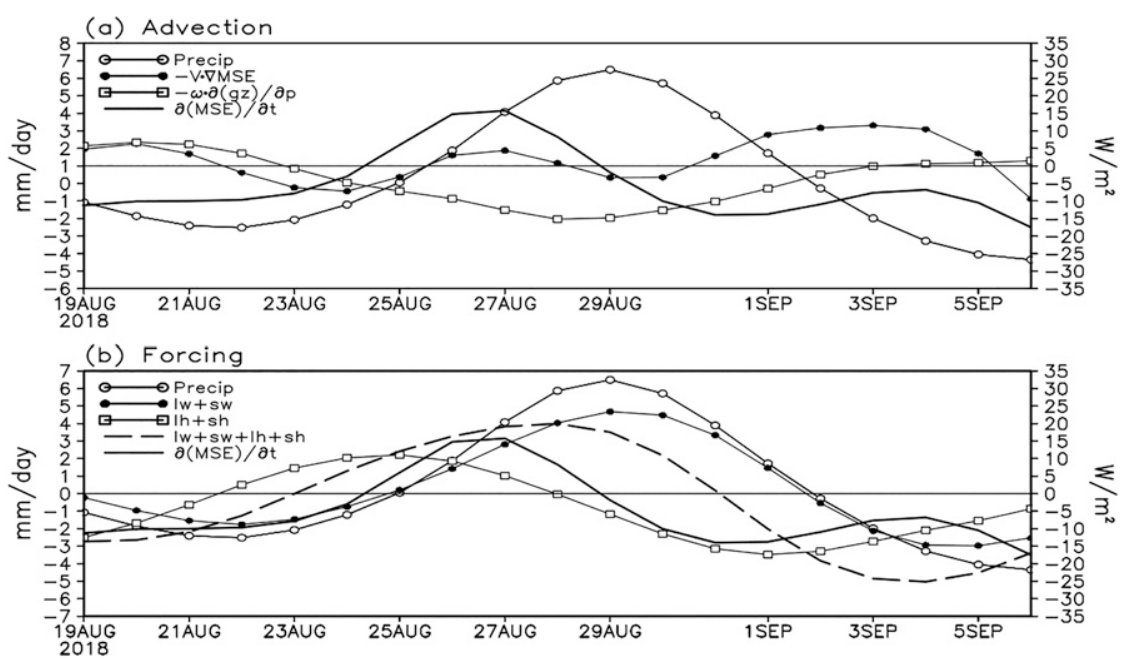

FIG. 10. Vertically integrated $m$ budget and precipitation anomalies averaged over South China: (a) advection terms, including horizontal advection (solid circles), vertical advection (open squares), and $m$ tendency (solid lines with no points) in $\mathrm{W} \mathrm{m}^{-2}$ (right $y$-axis). (b) Forcing terms, including longwave plus shortwave heating (solid circles), latent plus sensible heat fluxes (open squares), radiative heating plus heat fluxes (dashed lines with no points), and $m$ tendency (solid lines with no points) in $\mathrm{W} \mathrm{m}^{-2}$ (right $y$ axis). The left $y$ axis corresponds to the precipitation anomalies (open circles).

the surface latent heat flux, $\mathrm{SH}$ is the surface sensible heat flux, $\langle\mathrm{LW}\rangle$ represents the vertically integrated longwave heating rate, and $\langle\mathrm{SW}\rangle$ represents the vertically integrated shortwave heating rate. In this study, $\langle\mathrm{LW}\rangle$ and $\langle\mathrm{SW}\rangle$ were estimated by SLW minus TLW and TSW minus SSW, respectively. Here, SLW is the surface net LW, TLW is the topof-the-atmosphere net LW, SSW represents the surface net SW, and TSW represents the top-of-the-atmosphere net SW.

Of interest are the 12-30-day time-scale variations in the vertically integrated $m$ budget. Thus, a 12-30-day bandpass filter can be applied to Eq. (1) to produce the following:

$$
\begin{aligned}
\left\langle\frac{\partial m}{\partial t}\right\rangle_{\mathrm{HF}-\mathrm{ISO}}= & -\left\langle\omega \frac{\partial m}{\partial p}\right\rangle_{\mathrm{HF}-\mathrm{ISO}}-\langle\mathbf{v} \cdot \nabla m\rangle_{\mathrm{HF}-\mathrm{ISO}} \\
& +\mathrm{LH}_{\mathrm{HF}-\mathrm{ISO}}+\mathrm{SH}_{\mathrm{HF}-\mathrm{ISO}}+\langle\mathrm{LW}\rangle_{\mathrm{HF}-\mathrm{ISO}} \\
& +\langle\mathrm{SW}\rangle_{\mathrm{HF}-\mathrm{ISO}}+R_{m},
\end{aligned}
$$

where quantities with a subscript HF-ISO represent a 12-30-day bandpass-filtered field, and $R_{m}$ is the residual term.

Figure 10 shows that the vertically integrated $m$ tendency is approximately one-quarter phase ahead of the precipitation maximum. The recharge of $m$ occurred before the active phase and the discharge occurred during and after the PR1808 event, which is consistent with Figs. 7 and 8. In Fig. 10a, the horizontal advection $-\left\langle\mathbf{v} \cdot \nabla_{m}\right\rangle_{\mathrm{HF}-\text { ISO }}$ plays a role in the vertically integrated $m$ tendency, and the vertical advection term $-\langle\omega \partial m / \partial p\rangle_{\mathrm{HF}-\mathrm{ISO}}$ is nearly out of phase with the precipitation anomalies. In contrast, the LW plus SW lagged the vertically integrated $m$ change and was nearly in phase with the precipitation anomalies (Fig. 10b), which is due to the LW and SW cloud absorption. In addition, the LH plus SH was ahead of the change in $m$. This finding seems to indicate that the radiative heating and surface heat fluxes were not a key factor in the recharge of $m$ during the PR1808 event.

Considering the phase difference in $m$ with height (Fig. 4), we examined the low-level (1000-800 hPa) and midlevel (775$300 \mathrm{hPa}$ ) $m$. Then, we drew a Hovmöller diagram of the change in $m$ averaged from $20^{\circ}$ to $25^{\circ} \mathrm{N}$ (Fig. 11). This figure shows that the change in the midlevel $m$ propagated westward, all the way to SC, and even farther west. While the low-level $m$ change exhibited clear westward propagation in the western North Pacific to the east of South China, its changes moved eastward over South China. In addition, the low-level $m$ change preceded the change in the middle levels over the western North Pacific to the east of South China, whereas the former lagged the latter over South China.

Figure 12 shows the meridional propagation characteristics of the mid- and low-level $m$ tendencies. The $m$ tendency clearly moved southward from higher latitudes, but only the low-level tendency propagated to South China (Fig. 12a). This finding implies that the low-level $m$ change was mainly regulated by higherlatitude disturbances during the PR1808 event, while the midlevel $m$ tendency was modulated by the westward-propagating HF-ISO.

\section{Relative roles}

\section{a. Effect of advection}

Since the vertically integrated $m$ change (represented by the crosses in Fig. 11) was in phase with the midlevel $m$ tendency, the question remained as to why the latter propagated westward to South China. Figure 13 shows a Hovmöller diagram of the midlevel $m$ budget and precipitation anomalies. In Fig. 13a, the midlevel $m$ change, as well as $\langle\partial m / \partial t\rangle_{\mathrm{HF}-\mathrm{ISO}}$, was approximately one-quarter phase ahead of the convection center. Furthermore, meridional advection $-\langle v \partial m / \partial y\rangle_{\mathrm{HF}-\mathrm{ISO}}$ 


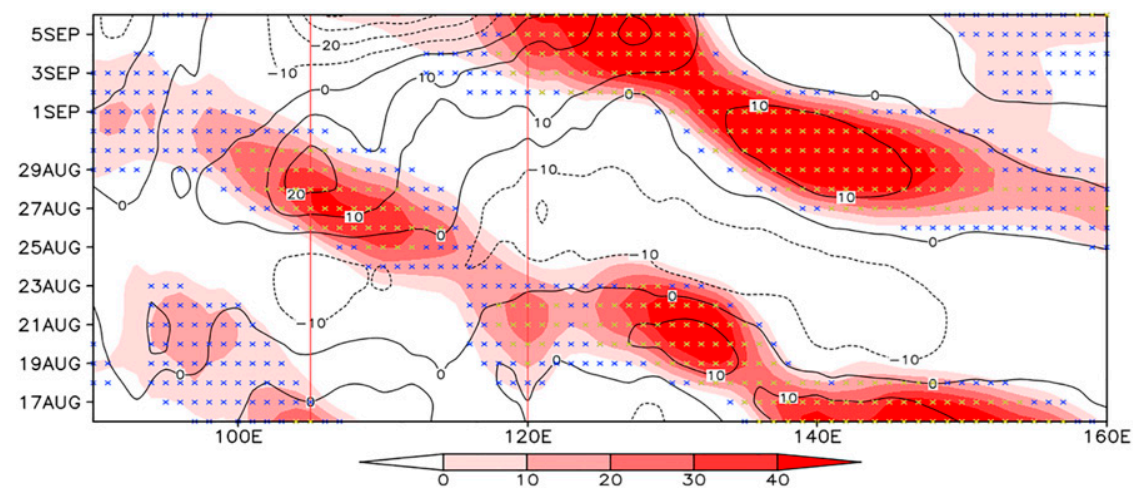

FIG. 11. Hovmöller diagram of the midlevel (775-300 hPa, shading), low-level (1000-800 $\mathrm{hPa}$, contours), and vertically integrated $(1000-100 \mathrm{hPa}$, crosses $) m$ tendencies $\left(\mathrm{W} \mathrm{m}^{-2}\right)$ averaged from $20^{\circ}$ to $25^{\circ} \mathrm{N}$. The area between the two red lines represents South China. Blue crosses denote values $>0$, and yellow crosses represent values $>10 \mathrm{~W} \mathrm{~m}^{-2}$.

(Fig. 13c) and vertical advection $-\langle\omega \partial m / \partial p\rangle_{\mathrm{HF}-\mathrm{ISO}}$ (Fig. 13d) were out of phase with the precipitation anomalies, while zonal advection $-\langle u \partial m / \partial x\rangle_{\mathrm{HF}-\mathrm{ISO}}$ (Fig. 13b) was consistent with the pattern of $m$ tendency in Fig. 13a. These relationships imply that the midlevel $m$ change was mainly caused by the zonal advection of $m$.

Considering the scale interactions, following Hsu et al. (2011), we separated the anomalous fields into three components- the LF ( $\geq 30$ days), HF-ISO (12-30 days), and synoptic-scale $(<12$ days $)$ components:

$$
A=\bar{A}+A^{\prime}+A^{\prime \prime},
$$

where $A$ represents the anomalous field, the overbar denotes the LF component, the prime denotes the HF-ISO field, and the double prime denotes the synoptic-scale field. Thus, for good approximation, $(u \partial m / \partial x)_{\mathrm{HF}-\mathrm{ISO}}$ can be written as

$$
\begin{aligned}
\left(u \frac{\partial m}{\partial x}\right)_{\mathrm{HF}-\mathrm{ISO}} & \approx\left(u^{\prime \prime} \frac{\partial m^{\prime \prime}}{\partial x}\right)_{\mathrm{HF}-\mathrm{ISO}}+\left(u^{\prime \prime} \frac{\partial \bar{m}}{\partial x}\right)_{\mathrm{HF}-\mathrm{ISO}} \\
& +\left(\bar{u} \frac{\partial m^{\prime \prime}}{\partial x}\right)_{\mathrm{HF}-\mathrm{ISO}}+\left(\bar{u} \frac{\partial \bar{m}}{\partial x}\right)_{\mathrm{HF}-\mathrm{ISO}} \\
& +u^{\prime} \frac{\partial m_{\mathrm{JJASO}}}{\partial x}+u_{\mathrm{JJASO}} \frac{\partial m^{\prime}}{\partial x},
\end{aligned}
$$

where quantities with a subscript JJASO represent a mean field from June to October, which is constant in time. Thus, none of the time scales of any variables are changed due to the mean fields. Since we were focusing on the HF-ISO time scale, only the terms $u^{\prime} \partial m_{\mathrm{JJASO}} / \partial x$ and $u_{\mathrm{JJASO}} \partial m^{\prime} / \partial x$ associated with the mean field were retained.

The different terms contributing to the middle tropospheric $m$ change are shown in Fig. 14. One can see from Fig. 14a that the
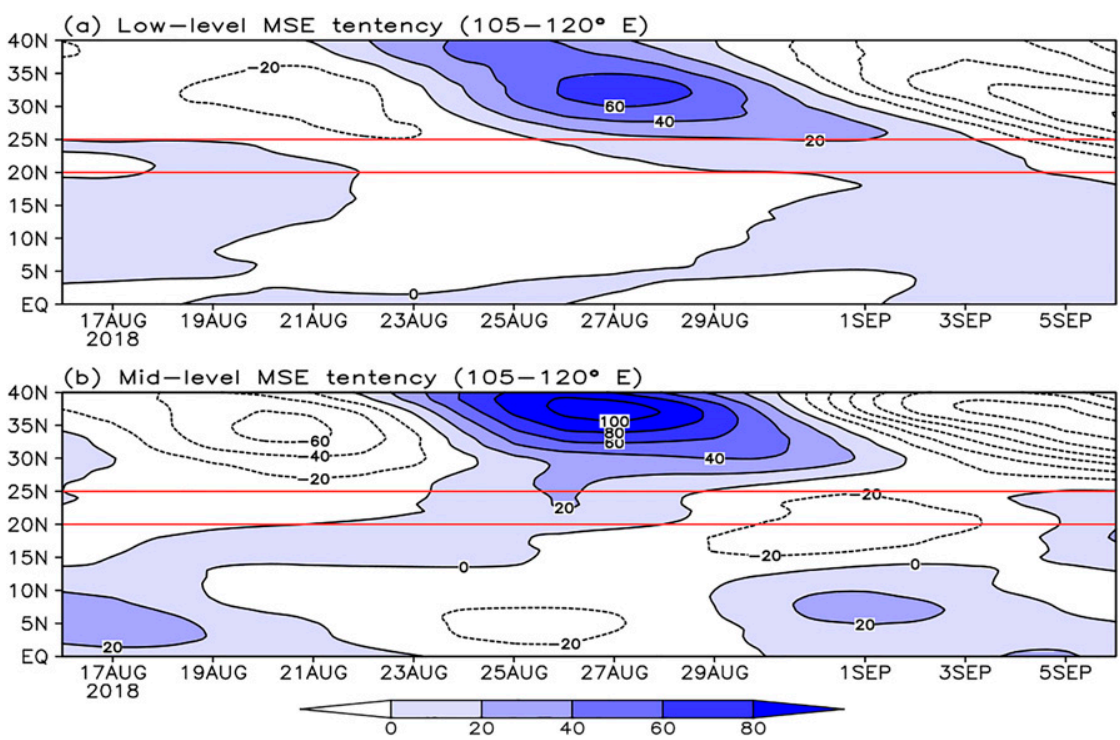

FIG. 12. Hovmöller diagram of (a) low-level (1000-800 hPa) and (b) midlevel (775-300 hPa) $m$ tendencies $\left(\mathrm{W} \mathrm{m}^{-2}\right)$ averaged from $105^{\circ}$ to $120^{\circ} \mathrm{E}$. The area between the two red lines represents South China. 
(a) $\partial(M S E) / \partial t$

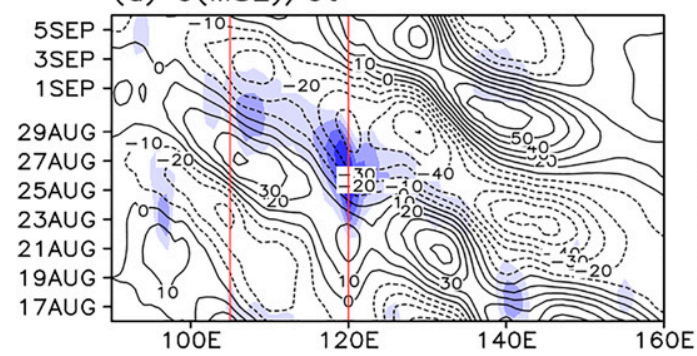

(c) $-v \cdot \partial(M S E) / \partial y$

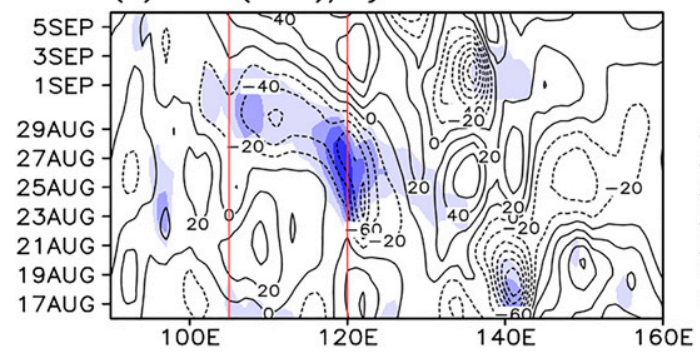

(b) $-u \cdot \partial(M S E) / \partial x$

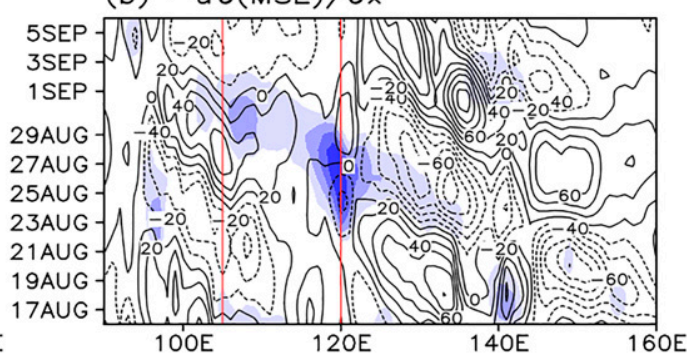

(d) $-\omega \cdot \partial(M S E) / \partial p$

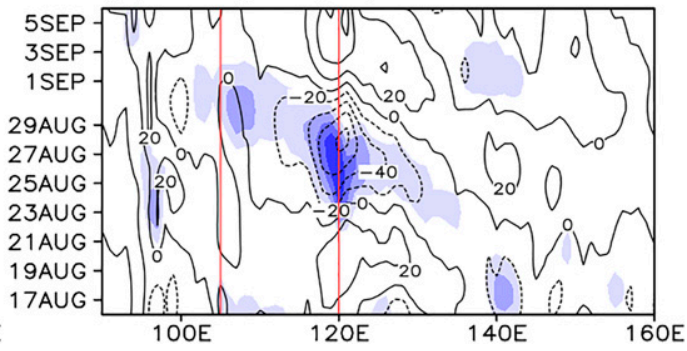

FIG. 13. Hovmöller diagram of the midlevel (a) $m$ change (contours, $\mathrm{W} \mathrm{m}^{-2}$ ), (b) zonal advection (contours, $\mathrm{W} \mathrm{m}^{-2}$ ), (c) meridional advection (contours, $\mathrm{W} \mathrm{m}^{-2}$ ), and (d) vertical advection (contours, $\mathrm{W} \mathrm{m}^{-2}$ ) averaged from $20^{\circ}$ to $25^{\circ} \mathrm{N}$. The shaded areas denote the ISO precipitation anomalies $\left(\mathrm{mm} \mathrm{day}^{-1}\right)$. The area between the two red lines represents South China.

eddy term $\left(u^{\prime \prime} \partial m^{\prime \prime} / \partial x\right)_{\mathrm{HF}-\mathrm{ISO}}$ exhibited a noticeably different pattern from the $m$ tendency (Fig. 11), which implies that the eddy term contributed little to the $m$ change. The terms $u^{\prime}\left(\partial m_{\mathrm{JJASO}} / \partial x\right)$ and $u_{\mathrm{JJASO}} \partial m^{\prime} / \partial x$ were almost out of phase with the $m$ tendency, especially over South China (Figs. 14e,f). This finding indicates that the role of advection from the mean states may have been negligible. Overall, the terms $(\bar{u} \partial \bar{m} / \partial x)_{\mathrm{HF}-\mathrm{ISO}}$, $\left(\bar{u} \partial m^{\prime \prime} / \partial x\right)_{\mathrm{HF}-\mathrm{ISO}}$, and $\left(u^{\prime \prime} \partial \bar{m} / \partial x\right)_{\mathrm{HF}-\mathrm{ISO}}$ each contributed to the $m$ change to some extent (Figs. 14b,c,e).

\section{b. Effect of forcing}

Whereas the role of surface heat fluxes and radiative heating in $m$ change averaged over South China was mentioned above (Fig. 10b), the regional average results could not reflect the characteristics of $m$ change propagating westward. Figure 15 displays the time-space cross section of the surface heat fluxes and radiative heating. In Figs. 15a and b, both the longwave and shortwave radiation were in phase with the precipitation, but lagged the $m$ change, which is consistent with Fig. 10b. The eastward propagation of surface latent and sensible heat (Figs. 15c and d) was significant, which was opposite the westward mode of the $m$ change or precipitation, although the heat fluxes contributed to the positive $m$ change over South China as shown in Fig. 10b. This finding implies that the forcing related to surface heat fluxes and radiative heating contributed little to the $m$ change during the PR1808 event.

\section{c. Relative roles}

As mentioned above, the PR1808 event was closely related to the $m$ recharge, namely, a positive $m$ change. To calculate the net contribution of the various terms to the $m$ change in Eq. (2), we introduced the concept of cumulative contribution, i.e., during the PR1808 event (21 August to 3 September, as shown in
Fig. 3f), the terms in Eq. (2) were projected on the positive phase of the $m$ change, and the values were accumulated over the entire process and domain (e.g., 21 August to 3 September, $105^{\circ}-$ $140^{\circ} \mathrm{E}$ ). The ratio of accumulated values to cumulative positive $m$ change is the cumulative contribution. In Fig. 16a, the $m$ change was mainly due to the effect of the zonal advection of $m$ during the PR1808 event. $R_{m}$ also provided a certain contribution to the positive $m$ tendency, which nearly balanced the meridional advection (Fig. 16a). Similarly, we calculated the relative contributions of the terms in Eq. (4) to the zonal advection of $m$, as shown in Fig. 16b. This finding revealed that advection by the LF zonal flow across the LF $m$ gradient $(\bar{u} \partial \bar{m} / \partial x)_{\mathrm{HF}-\mathrm{ISO}}$ and interactions between HF and LF zonal wind and $m$ gradient $\left(\bar{u} \partial m^{\prime \prime} / \partial x\right)_{\mathrm{HF}-\mathrm{ISO}}$ and $\left(u^{\prime \prime} \partial \bar{m} / \partial x\right)_{\mathrm{HF}-\mathrm{ISO}}$ were the most important contributors. Hsu et al. (2011) and Maloney (2009) attributed the mean state to the LF component, and thus the sum of the last three terms on the right in Eq. (4) constitutes the contribution of the LF components, which somehow offset each other. Thus, the contribution of the LF components was small. In Fig. 16b, $R_{u m}$ was very small, implying that the zonal advection could be nearly reproduced by the sum of the six terms on the right side in Eq. (4) in the PR1808 event (figure not shown).

\section{Enhancement by high-latitude disturbances}

From the above analysis, we determined that the midlevel $m$ over South China was mainly attributed to westward-propagating processes (Figs. 11 and 12). Since the column-integrated $m$ was nearly in phase with the precipitation over South China during the PR1808 event (Fig. 4), the westward propagation of the vertically integrated $m$ on the HF-ISO time scale provided a significant contribution to the PR1808 event (these propagation 
(a) $-u_{n r} \partial\left(M S E_{n t}\right) / \partial x$

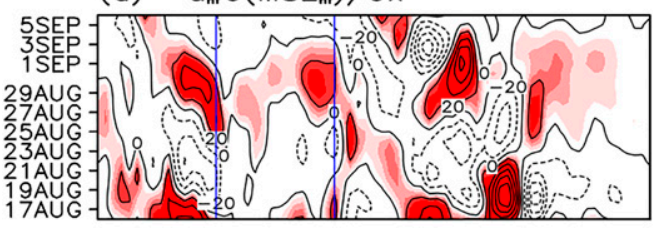

(c) $-u_{1 r} \partial\left(M S E_{n t}\right) / \partial x$

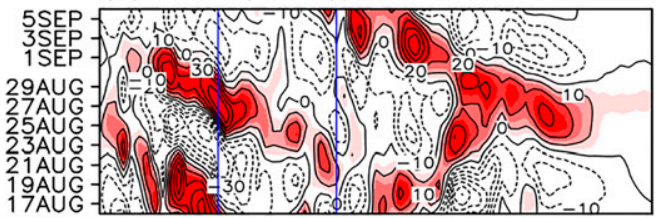

(e) $-u_{150} \cdot \partial\left(M S E_{\text {suso }}\right) / \partial x$
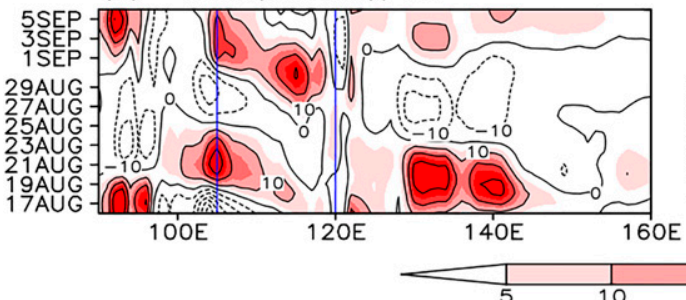

(b) $-u_{10} \partial\left(M S E_{11}\right) / \partial x$

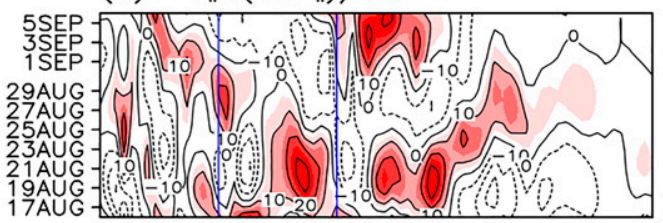

(d) $-u_{n e} \partial\left(M S E_{11}\right) / \partial x$

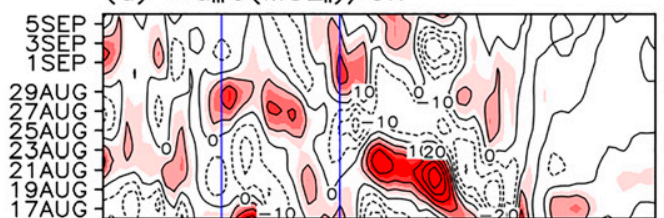

(f) $-u_{\text {suso }} \cdot \partial\left(M E_{1 s o}\right) / \partial x$

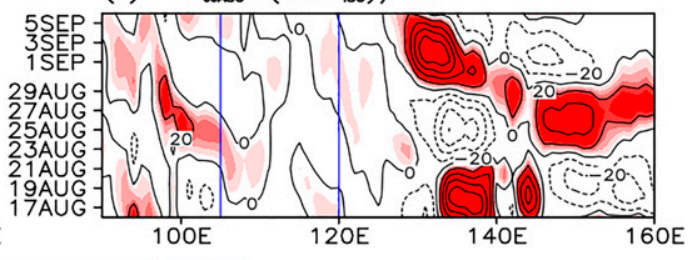

FIG. 14. Contributions of scale interaction to the zonal advection of midlevel $m$ : (a) advection of HF $m$ by HF zonal flow $\left(\mathrm{W} \mathrm{m}^{-2}\right)$, (b) advection of LF $m$ by LF zonal flow $\left(\mathrm{W} \mathrm{m}^{-2}\right.$ ), (c) advection of HF $m$ by LF zonal flow $\left(\mathrm{W} \mathrm{m}^{-2}\right)$, (d) advection of LF $m$ by HF zonal flow $\left(\mathrm{W} \mathrm{m}^{-2}\right.$ ), (e) advection of mean $m$ by intraseasonal zonal wind $\left(\mathrm{W} \mathrm{m}^{-2}\right)$, and (f) advection of intraseasonal $m$ by mean zonal wind $\left(\mathrm{W} \mathrm{m}^{-2}\right)$ averaged from $20^{\circ}$ to $25^{\circ} \mathrm{N}$. The area between the two blue lines represents South China.

processes and related mechanisms have been discussed above in detail). However, although the influence of higher latitudes can be seen in Figs. 5 and 6, it is unclear how the higher-latitude disturbances affected the PR1808 event.

(a) LW

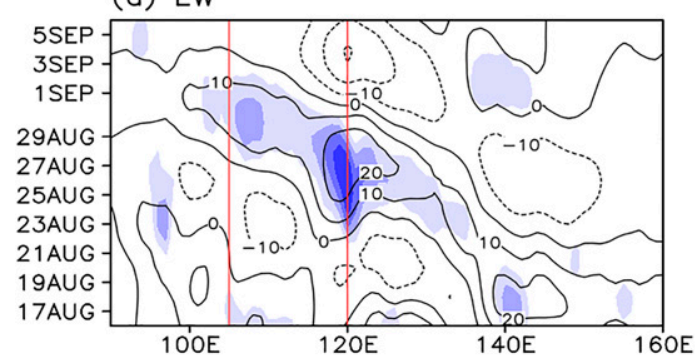

(c) $\mathrm{LH}$

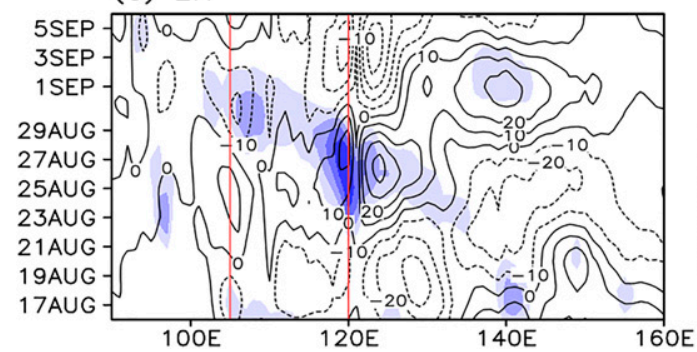

Next, we analyzed the impact of high-latitude disturbances on the PR1808 event. In Fig. 5, the low-level cyclonic anomaly over South China originated from the southwestward propagation of high-latitude disturbances, while the high-level anomaly originated

FIG. 15. As in Fig. 13, but for (a) longwave radiation (contours, $\mathrm{W} \mathrm{m}^{-2}$ ), (b) shortwave radiation (contours, $\mathrm{W} \mathrm{m} \mathrm{m}^{-2}$ ), (c) surface latent heat flux (contours, $\mathrm{W} \mathrm{m}^{-2}$ ), and (d) surface sensible heat flux (contours, $\mathrm{W} \mathrm{m}^{-2}$ ) averaged from $20^{\circ}$ to $25^{\circ} \mathrm{N}$.

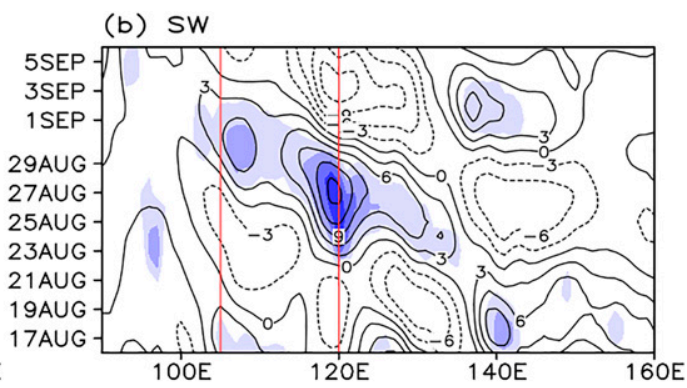

(d) $\mathrm{SH}$

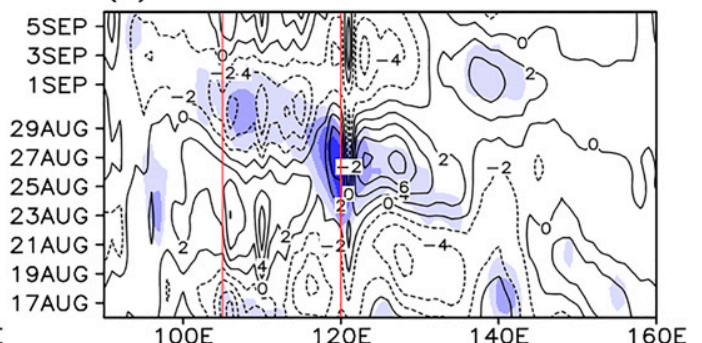




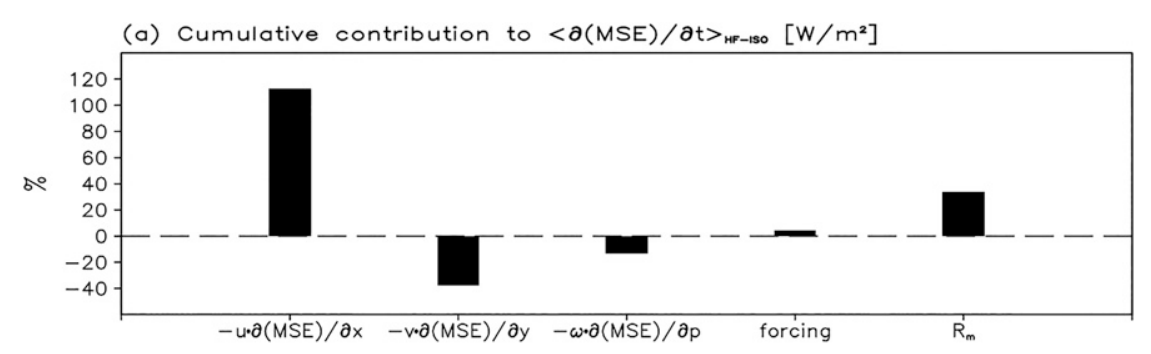

(b) Cumulative contribution to $-\langle u \cdot \partial(M S E) / \partial \times\rangle_{H F-1 s o}\left[\mathrm{~W} / \mathrm{m}^{2}\right]$

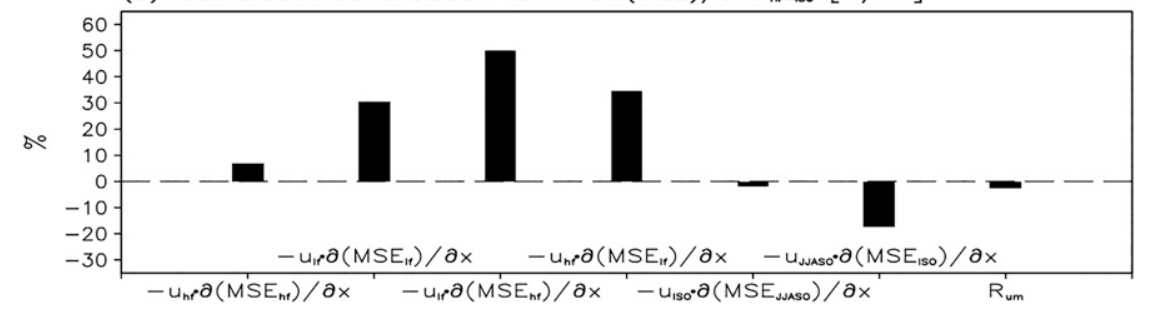

FIG. 16. (a) Relative roles of the terms in Eq. (2) to the positive $m$ change and (b) relative contributions of the terms in Eq. (4) to the zonal advection of $m$. The right bar, labeled $R$, is the residual term.

from southwestward-propagating disturbances at the same latitude (Fig. 6). To understand the source of the vorticity disturbances more objectively, we created Figs. 17 and 18 to illustrate the meridional and zonal wavelength-period power spectra of low- and high-level vorticities from 1 August to 30 September. These figures show that low-level vorticity disturbance originated from higher latitudes, while the high-level disturbance came from the southwestward propagation of high-latitude disturbances. Then, an induced southward-propagating baroclinic vorticity enhanced the PR1808 event as shown in Fig. 19.

Some studies have pointed out that southward propagation of vorticity disturbances from higher latitudes would affect the ISO over LYRB (e.g., Yang et al. 2010; Hui and Fang 2016b) and South China (Li et al. 2015; Zheng and Huang 2018) that is consistent with our results, but the tropical effect was not significant in this case.

\section{Summary and discussion}

The PR1808 event was closely linked to the 12-30-day ISO, which is an HF-ISO process, while the related characteristics were significantly different from previous studies. First, the PR1808 event was affected by higher-latitude waves rather than tropical waves. In this case, the disturbances from the higher latitudes enhanced the persistent rainfall over South China through the southward-propagating baroclinic vorticity. Second, the precipitation anomaly propagated westward during the PR1808 event, while northward or northwestward propagations have been found in many previous studies (Mao and Chan 2005; Chen et al. 2015; Li et al. 2015; Gao et al. 2016; Hsu et al. 2016; Zheng and Huang 2018;Zheng et al. 2020). This study investigated the MSE budget during the PR1808 event. $m$ was recharged prior to the peak precipitation, i.e., during the suppressed phase and developing phase. Then, discharge of $m$ occurred during and after the precipitation maximum, i.e., in the active phase and decaying phase. These findings indicate that the recharge-discharge cycle of $m$ played an important role in regulating the HF-ISO process of the PR1808 event. However, the midlevel $m$ tendency, not the low-level one, controlled the column-integrated $m$ change in this case, which is quite different from previous studies (Kim et al. 2014; Sobel et al. 2014; Adames and Wallace 2015; Jiang 2017; Wang and Li 2020). There is no low-level $m$ (or specific humidity) change ahead of ISO convection, implying that not all ISOs are developed by shallow convection, and a midlevel $m$ (or specific humidity) anomaly also controls ISO convection development. This finding is consistent with the result from a climate model (Maloney 2009), in which shallow convection was not a key factor in the development of ISO, although the low-level $m$ (or specific humidity) still had a lead phase. Therefore, for some persistent rainfall events (e.g., PR1808), lower low-level moisture convergence is not a key factor in developing the associated ISO processes.

Yan et al. (2019) argued that the strength of the South Asian high and western Pacific subtropical high modulate the generation of the two types of HF-ISOs differently. One originates from $110^{\circ}$ to $140^{\circ} \mathrm{E}$ and propagates westward to South China with a notable impact on the regional rainfall, while the other initiates from $160^{\circ} \mathrm{E}$ to the date line and does not significantly affect South China rainfall. Furthermore, Yan et al. (2019) pointed out that mutually stronger highs favor the westward-propagating HF-ISO. As analyzed above, the South Asian high and western Pacific subtropical high were stronger before the active phase of the PR1808 event (Figs. 5-7), thus favoring a westward-propagating HF-ISO.

In addition, the westward shift of the $m$ tendency played a key role in the westward-propagating HF-ISO in this case, while the recharge of midlevel $m$, controlling the columnintegrated $m$ change, was mainly caused by zonal advection. For the zonal advection of $m$, the main contribution came from advection by the LF zonal flow across the LF $m$ gradient $(\bar{u} \partial \bar{m} / \partial x)_{\mathrm{HF}-\mathrm{ISO}}$, and interactions between the HF and LF zonal wind and $m\left(\bar{u} \partial m^{\prime \prime} / \partial x\right)_{\mathrm{HF}-\mathrm{ISO}}$ and $\left(u^{\prime \prime} \partial \bar{m} / \partial x\right)_{\mathrm{HF}-\mathrm{ISO}}$ (Fig. 16b). 

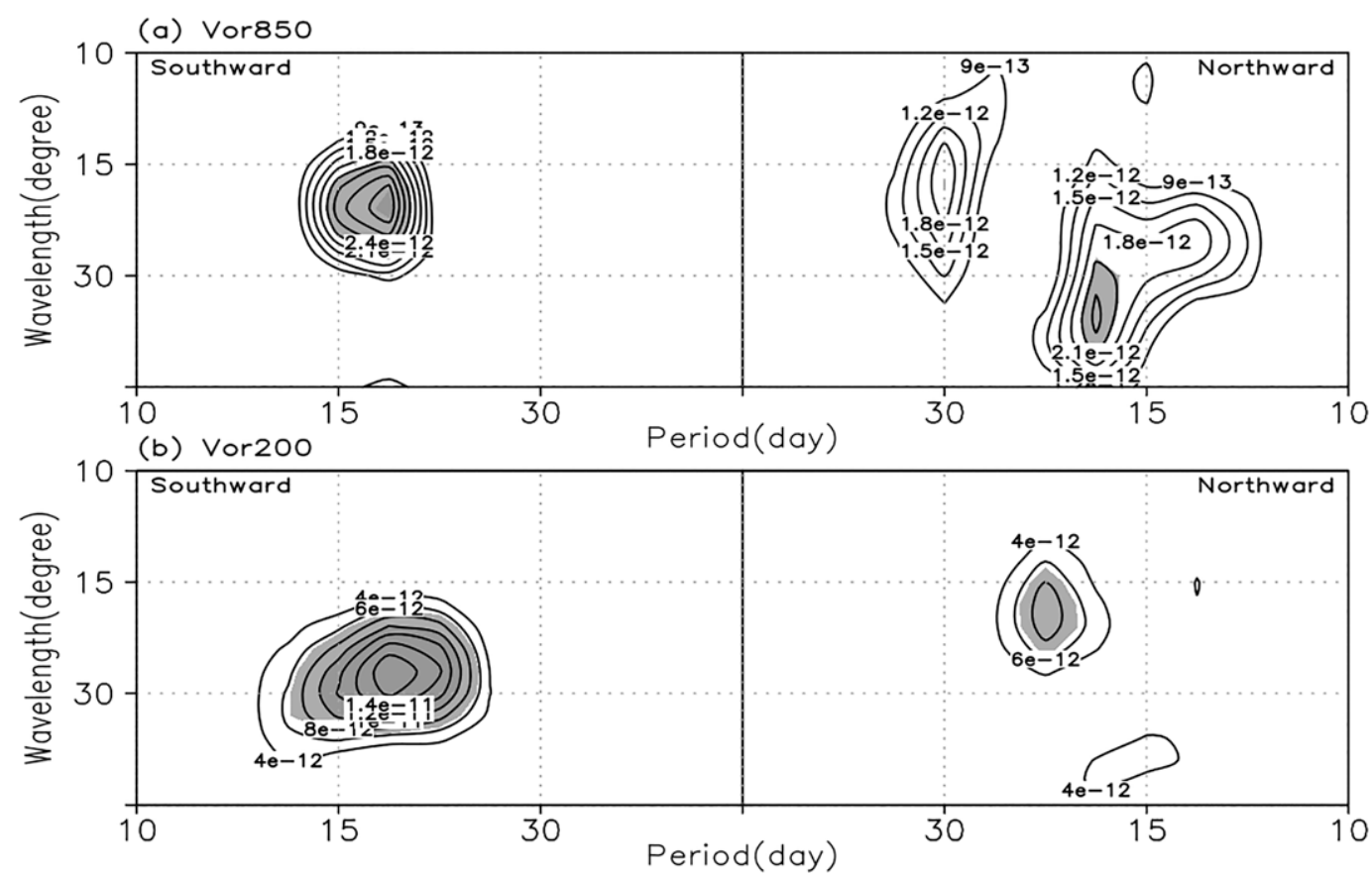

FIG. 17. Meridional wavelength-period power spectrum of (a) 850- and (b) 200-hPa vorticity averaged from $105^{\circ}$ to $120^{\circ} \mathrm{E}$ during the period from 1 August to 30 September. The shaded area indicates the power spectra exceeding the $95 \%$ confidence level.

In contrast, the forcing, including the radiative heating and surface heat fluxes, seems to have largely contributed to the $m$ tendency over South China (Fig. 10b). While the surface heat fluxes show a propagation opposite to the change in $m$ (Figs. 15c,d), and the radiative heating and ISO precipitation were nearly in phase (Figs. 15a,b), the forcing contributed little to the $m$ tendency over the entire domain during the PR1808 period (Fig. 16a). This result implies that
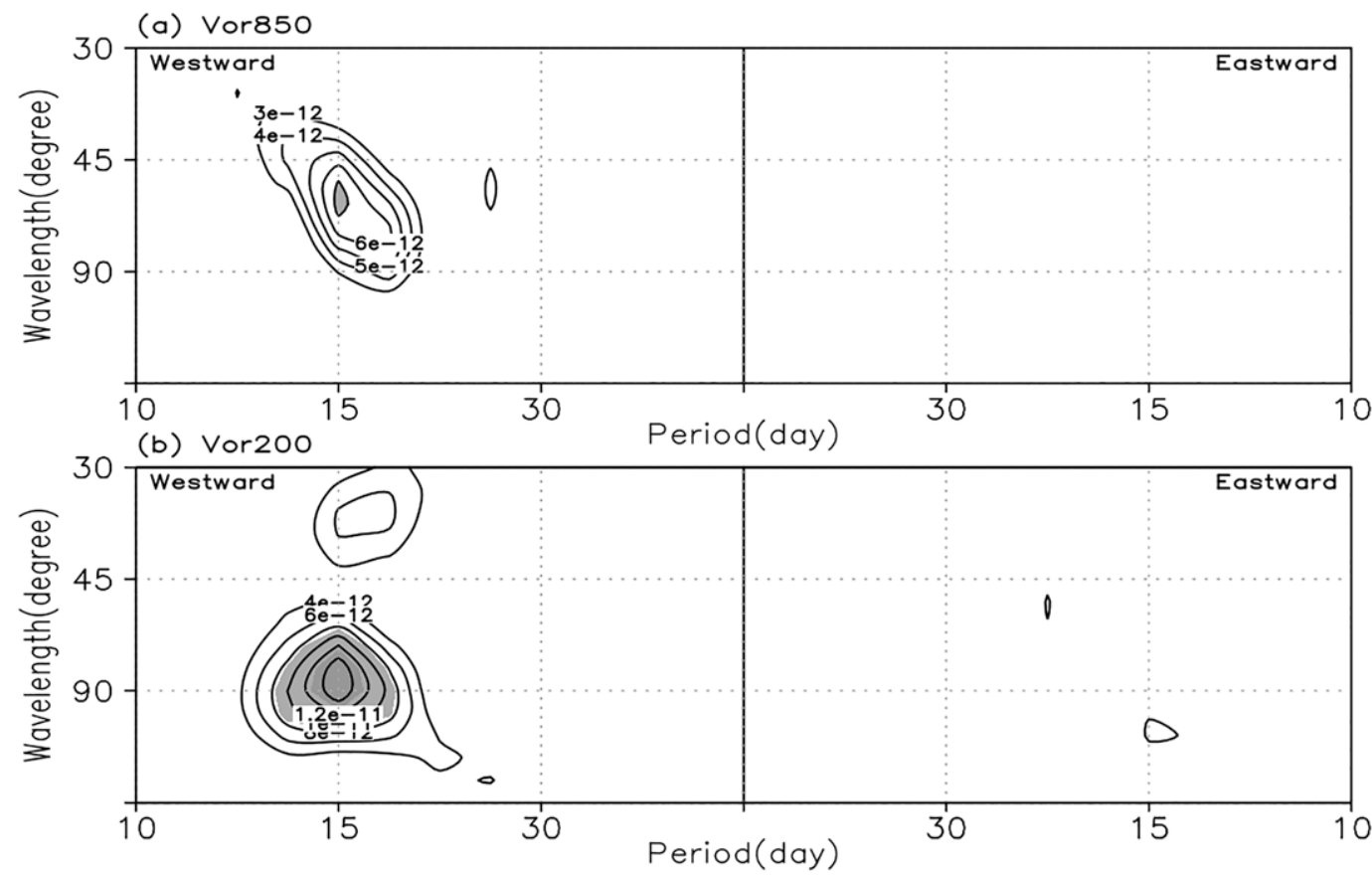

FIG. 18. As in Fig. 17, but for the zonal wavelength-period power spectrum of vorticity averaged from $20^{\circ}$ to $25^{\circ} \mathrm{N}$. 


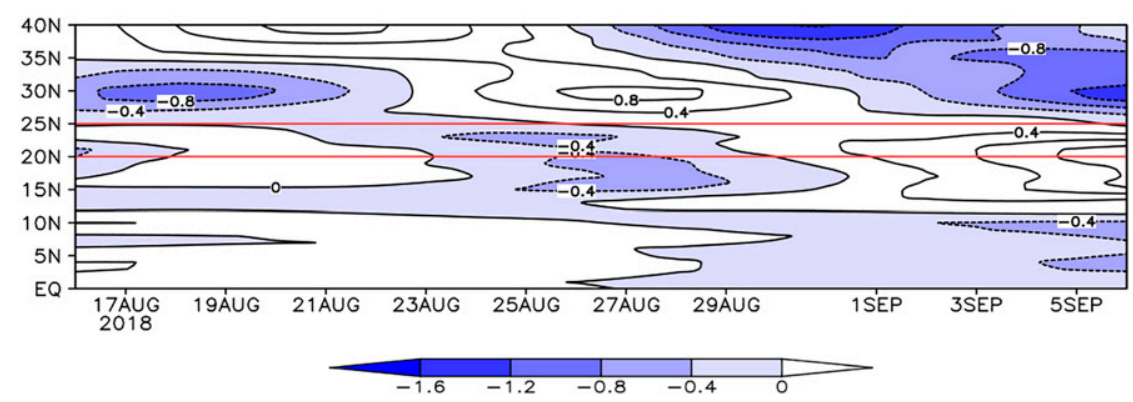

FIG. 19. Hovmöller diagram of the baroclinic vorticity $\left(10^{-5} \mathrm{~s}^{-1}\right.$, defined as the vorticity difference between 200 and $850 \mathrm{hPa}$ ) averaged from $105^{\circ}$ to $120^{\circ} \mathrm{E}$. The area between the two red lines represents South China.

the forcing was not essential for the westward propagation of the change in $m$.

In this case, higher-latitude disturbances played an important role in the PR1808 event; in other words, the tropical disturbances were relatively weak. Generally, when the South China HF-ISO is weaker, the related tropical disturbances are not evident, and the higher-latitude disturbances are relatively strong (Li et al. 2015). In Figs. 2 and 3, the HF and LF components of precipitation over South China had comparable intensities, while the intensity of the HF component is generally much larger than that of the LF component (Figs. 1c,d). Thus, the weaker HF-ISO intensity would lead to weaker tropical disturbances in the PR1808 event.

Acknowledgments. This work was supported by the National Key R\&D Program of China (Grant 2018YFC1505801), the Guangdong Basic and Applied Basic Research Foundation (Grant 2021A1515011399), and the National Natural Science Foundation of China (Grant 41705089). The ERA-Interim data were obtained from https://apps.ecmwf.int/datasets/data/ interim-full-daily/. The GPI data were obtained from http:// ftp.cpc.ncep.noaa.gov/precip/gpi.

\section{REFERENCES}

Adames, Á. F., and J. M. Wallace, 2015: Three-dimensional structure and evolution of the moisture field in the MJO. J. Atmos. Sci., 72, 3733-3754, https://doi.org/10.1175/JAS-D-15-0003.1.

— coupled moisture wave: Theory and observations. J. Atmos. Sci., 73, 913-941, https://doi.org/10.1175/JAS-D-15-0170.1.

Charney, J. G., and A. Ellassen, 1964: On the growth of the hurricane depression. J. Atmos. Sci., 21, 68-75, https://doi.org/ 10.1175/1520-0469(1964)021<0068:OTGOTH>2.0.CO;2.

Chen, J., Z. Wen, R. Wu, Z. Chen, and P. Zhao, 2015: Influences of northward propagating 25-90-day and quasi-biweekly oscillations on eastern China summer rainfall. Climate Dyn., 45, 105-124, https://doi.org/10.1007/s00382-014-2334-y.

Dee, D. P., and Coauthors, 2011: The ERA-Interim reanalysis: Configuration and performance of the data assimilation system. Quart. J. Roy. Meteor. Soc., 137, 553-597, https://doi.org/ 10.1002/qj.828.

Gao, J., H. Lin, L. You, and S. Chen, 2016: Monitoring early-flood season intraseasonal oscillations and persistent heavy rainfall in South China. Climate Dyn., 47, 3845-3861, https://doi.org/ 10.1007/s00382-016-3045-3.
Gao, Y., N. P. Klingaman, C. A. Demott, and P.-C. Hsu, 2019: Diagnosing ocean feedbacks to the BSISO: SST-modulated surface fluxes and the moist static energy budget. J. Geophys. Res. Atmos., 124, 146-170, https://doi.org/10.1029/2018JD029303.

Hendon, H. H., and B. Liebmann, 1990: The intraseasonal (3050 day) oscillation of the Australian summer monsoon. J. Atmos. Sci., 47, 2909-2924, https://doi.org/10.1175/15200469(1990)047<2909:TIDOOT>2.0.CO;2.

Hsu, P.-C., T. Li, and C.-H. Tsou, 2011: Interactions between boreal summer intraseasonal oscillations and synoptic-scale disturbances over the western North Pacific. Part I: Energetics diagnosis. J. Climate, 24, 927-941, https://doi.org/10.1175/2010JCLI3833.1.

_, J.-Y. Lee, and K.-J. Ha, 2016: Influence of boreal summer intraseasonal oscillation on rainfall extremes in southern China. Int. J. Climatol., 36, 1403-1412, https://doi.org/10.1002/joc.4433.

Hu, L., J. He, and S. Gao, 2007: An analysis of large-scale condition for persistent heavy rain in South China (in Chinese). J. Nanjing Ins. Meteor., 30 (3), 345-351.

Huffman, G. J., R. F. Adler, M. M. Morrissey, D. T. Bolvin, S. Curtis, R. Joyce, B. McGavock, and J. Susskind, 2001: Global precipitation at one-degree daily resolution from multisatellite observations. J. Hydrometeor., 2, 36-50, https://doi.org/10.1175/ 1525-7541(2001)002<0036:GPAODD > 2.0.CO;2.

Hui, P., and J. Fang, 2016a: Comparison of the multi-scale features in two persistent heavy rainfall events in the middle and lower reaches of Yangtze River. J. Meteor. Res., 30, 528-546, https:// doi.org/10.1007/s13351-016-6028-8.

— and low latitudes on two persistent heavy rainfall events in the middle and lower reaches of the Yangtze River. J. Meteor. Res., 30, 662-677, https://doi.org/10.1007/s13351016-6082-2.

Imada, Y., S. Kanae, M. Kimoto, M. Watanabe, and M. Ishii, 2015: Predictability of persistent Thailand rainfall during the mature monsoon season in 2011 using statistical downscaling of CGCM seasonal prediction. Mon. Wea. Rev., 143, 1166-1178, https://doi.org/10.1175/MWR-D-14-00228.1.

Jiang, X., 2017: Key processes for the eastward propagation of the Madden-Julian oscillation based on multimodel simulations. J. Geophys. Res. Atmos., 122, 755-770, https://doi.org/10.1002/ 2016JD025955.

— T. Li, and B. Wang, 2004: Structures and mechanisms of the northward-propagating boreal summer intraseasonal oscillation. J. Climate, 17, 1022-1039, https://doi.org/10.1175/15200442(2004)017<1022:SAMOTN>2.0.CO;2.

Kemball-Cook, S. R., and B. Wang, 2001: Equatorial waves and air-sea interaction in the boreal summer intraseasonal 
oscillation. J. Climate, 14, 2923-2942, https://doi.org/10.1175/ 1520-0442(2001)014<2923:EWAASI >2.0.CO;2.

- and B. C. Weare, 2001: The onset of convection in the MaddenJulian oscillation. J. Climate, 14, 780-793, https://doi.org/10.1175/ 1520-0442(2001)014<0780:TOOCIT>2.0.CO;2.

Kim, D., J. Kug, and A. H. Sobel, 2014: Propagating versus nonpropagating Madden-Julian oscillation events. J. Climate, 27, 111-125, https://doi.org/10.1175/JCLI-D13-00084.1.

Krishnamurthy, V., and J. Shukla, 2007: Intraseasonal and seasonally persisting patterns of Indian monsoon rainfall. J. Climate, 20, $3-$ 20, https://doi.org/10.1175/JCLI3981.1.

Li, C., T. Li, D. Gu, A. Lin, and B. Zheng, 2015: Relationship between summer rainfall anomalies and sub-seasonal oscillations in South China. Climate Dyn., 44, 423-439, https:// doi.org/10.1007/s00382-014-2172-y.

_ _ - and B. Zheng, 2018: Characteristic interdecadal change of quasi-biweekly and intraseasonal oscillations of summer convection over the South China Sea and the western Pacific. Dyn. Atmos. Oceans, 83, 41-52, https:// doi.org/10.1016/j.dynatmoce.2018.05.006.

Li, K., W. Yu, T. Li, V. S. N. Murty, S. Khokiattiwong, T. R. Adi, and S. Budi, 2013: Structures and mechanisms of the first branch northward-propagating intraseasonal oscillation over the tropical Indian Ocean. Climate Dyn., 40, 1707-1720, https://doi.org/10.1007/s00382012-1492-z.

Li, W., P.-C. Hsu, J. He, Z. Zhu, and W. Zhang, 2016: Extended-range forecast of spring rainfall in southern China based on the Madden-Julian Oscillation. Meteor. Atmos. Phys., 128, 331-345, https://doi.org/10.1007/ s00703-015-0418-9.

Li, X., Y. Luo, and Z. Guan, 2014: The persistent heavy rainfall over southern China in June 2010: Evolution of synoptic systems and the effects of the Tibetan Plateau heating. $J$. Meteor. Res., 28, 540-560, https://doi.org/10.1007/s13351014-3284-3.

Lin, A., C. Li, B. Zheng, and D. Gu, 2013: Variation characteristics of sustained torrential rain during the pre-flooding season in Guangdong and the associated circulation pattern (in Chinese). Acta Meteor. Sin., 71, 628-642.

—_, D. Gu, B. Zheng, C. Li, and J. Zhang, 2014: Anomalous transport of water vapor for sustained torrential rain and its variation (in Chinese). J. Trop. Meteor., 30, 10011010.

Liu, R., J. Sun, J. Wei, and S. Fu, 2016: Classification of persistent heavy rainfall events over South China and associated moisture source analysis. J. Meteor. Res., 30, 678-693, https:// doi.org/10.1007/s13351-016-6042-x.

Maloney, E. D., 2009: The moist static energy budget of a composite tropical intraseasonal oscillation in a climate model. J. Climate, 22, 711-729, https://doi.org/10.1175/ 2008JCLI2542.1.

Mao, J., and J. C. L. Chan, 2005: Intraseasonal variability of the South China Sea summer monsoon. J. Climate, 18, 2388-2402, https://doi.org/10.1175/JCLI3395.1.

Neelin, J. D., and I. M. Held, 1987: Modeling tropical convergence based on the moist static energy budget. Mon. Wea. Rev., 115,3-12, https://doi.org/10.1175/1520-0493(1987)115<0003: MTCBOT $>2.0 . \mathrm{CO} ; 2$.

Raymond, D. J., and Ž. Fuchs, 2009: Moisture modes and the Madden-Julian oscillation. J. Climate, 22, 3031-3046, https:// doi.org/10.1175/2008JCLI2739.1.
Ren, X., X.-Q. Yang, and X. Sun, 2013: Zonal oscillation of western Pacific subtropical high and subseasonal SST variations during Yangtze persistent heavy rainfall events. J. Climate, 26, 8929-8946, https://doi.org/10.1175/JCLI-D12-00861.1.

Sobel, A., and E. Maloney, 2012: An idealized semi-empirical framework for modeling the Madden-Julian oscillation. J. Atmos. Sci., 69, 1691-1705, https://doi.org/10.1175/JASD-11-0118.1.

- , and — 2013: Moisture modes and the eastward propagation of the MJO. J. Atmos. Sci., 70, 187-192, https://doi.org/ 10.1175/JAS-D-12-0189.1.

- S. Wang, and D. Kim, 2014: Moist static energy budget of the MJO during DYNAMO. J. Atmos. Sci., 71, 4276-4291, https:// doi.org/10.1175/JAS-D-14-0052.1.

Tian, S. F., and T. Yasunari, 1998: Climatological aspects and mechanism of spring persistent rains over central China. J. Meteor. Soc. Japan, 76, 57-71, https://doi.org/10.2151/ jmsj1965.76.1_57.

Wang, H., J. Sun, S. Zhao, and J. Wei, 2016: The multiscale factors favorable for a persistent heavy rain event over Hainan Island in October 2010. J. Meteor. Res., 30, 496-512, https://doi.org/ 10.1007/s13351-016-6005-2.

Wang, J., Z. Wen, R. Wu, and A. Lin, 2017: The impact of tropical intraseasonal oscillation on the summer rainfall increase over southern China around 1992/1993. Climate Dyn., 49, 1847-1863, https://doi.org/10.1007/s00382-0163425-8.

Wang, T., and T. Li, 2020: Diagnosing the column-integrated moist static energy budget associated with the northwardpropagating boreal summer intraseasonal oscillation. Climate Dyn., 54, 4711-4732, https://doi.org/10.1007/s00382020-05249-8.

Yan, X., S. Yang, T. Wang, E. D. Maloney, S. Dong, W. Wei, and S. He, 2019: Quasi-biweekly oscillation of the Asian monsoon rainfall in late summer and autumn: Different types of structure and propagation. Climate Dyn., 53, 6611-6628, https:// doi.org/10.1007/s00382-019-04946-3.

Yang, J., B. Wang, and Q. Bao, 2010: Biweekly and 21-30-day variations of the subtropical summer monsoon rainfall over the lower reach of the Yangtze RivebBasin. J. Climate, 23, 1146-1159, https://doi.org/10.1175/2009JCLI3005.1.

Zhang, D., B. Zheng, X. Wang, C. Cun, and Y. Zhao, 2015: Preliminary research on circulation patterns in the persistent heavy rain processes during the first rainy season in South China (in Chinese). Trans. Atmos. Sci., 38, 310320.

Zhang, J., L. Li, T. Zhou, and X. Xin, 2013: Evaluation of spring persistent rainfall over East Asia in CMIP3/CMIP5 AGCM simulations. Adv. Atmos. Sci., 30, 1587-1600, https://doi.org/ 10.1007/s00376-013-2139-7.

Zheng, B., and Y. Huang, 2018: Mechanisms of meridionalpropagating high-frequency intraseasonal oscillation associated with a persistent rainfall over South China. Mon. Wea. Rev., 146, 1475-1494, https://doi.org/10.1175/MWR-D-170260.1 .

—, and —, 2019: Mechanisms of northward-propagating intraseasonal oscillation over the South China Sea during the pre-monsoon period. J. Climate, 32, 3297-3311, https://doi.org/ 10.1175/JCLI-D-18-0391.1.

- A. Lin, J. Yuan, D. Gu, C. Li, and J. Liang, 2007: Study on the cause of Heavy Rain 200506 (HR0506) in Guangdong. J. Trop. Meteor., 13, 145-148. 
_- Y. Huang, C. Li, and A. Lin, 2020: How can 30-60-day ISO move from the South China Sea to Southern China? Climate Dyn., 54, 3613-3624, https://doi.org/10.1007/s00382-02005194-6.

Zhu, Z., and T. Li, 2017: The statistical extended-range (10-30day) forecast of summer rainfall anomalies over the entire China. Climate Dyn., 48, 209-224, https://doi.org/10.1007/ s00382-016-3070-2.
— J. He, and L. Qi, 2012: Seasonal transition of East Asian subtropical monsoon and its possible mechanism. J. Trop. Meteor., 18, 305-313.

—, S. Chen, K. Yuan, Y. Chen, S. Gao, and Z. Hua, 2017: Empirical subseasonal predicting summer rainfall anomalies over the middle and lower reaches of Yangtze River basin based on the atmospheric intraseasonal oscillation. Atmosphere, 8, 185, https://doi.org/10.3390/atmos8100185. 